University of Louisville

ThinkIR: The University of Louisville's Institutional Repository

Electronic Theses and Dissertations

8-2017

\title{
Cumulative trauma, emotion reactivity and salivary cytokine response following acute stress among healthy women.
}

Yvette Z. Szabo

University of Louisville

Follow this and additional works at: https://ir.library.louisville.edu/etd

Part of the Biological Psychology Commons, Clinical Psychology Commons, and the Oral Biology and Oral Pathology Commons

\section{Recommended Citation}

Szabo, Yvette Z., "Cumulative trauma, emotion reactivity and salivary cytokine response following acute stress among healthy women." (2017). Electronic Theses and Dissertations. Paper 2795.

https://doi.org/10.18297/etd/2795

This Doctoral Dissertation is brought to you for free and open access by ThinkIR: The University of Louisville's Institutional Repository. It has been accepted for inclusion in Electronic Theses and Dissertations by an authorized administrator of ThinkIR: The University of Louisville's Institutional Repository. This title appears here courtesy of the author, who has retained all other copyrights. For more information, please contact thinkir@louisville.edu. 


\title{
CUMULATIVE TRAUMA, EMOTION REACTIVITY AND SALIVARY CYTOKINE RESPONSE FOLLOWING ACUTE STRESS AMONG HEALTHY WOMEN
}

\author{
By \\ Yvette Z. Szabo, M.A. \\ B.S., San José State University, 2012 \\ M.A., University of Louisville, 2014

\begin{abstract}
A Dissertation
Submitted to the Faculty of the

College of Arts and Sciences at the University of Louisville in Partial Fulfillment of the Requirements for the Degree of
\end{abstract} \\ Doctor of Philosophy \\ in Clinical Psychology \\ Department of Psychological and Brain Sciences \\ University of Louisville \\ Louisville, Kentucky
}

August 2017 
Copyright 2017 by Yvette Z. Szabo

All rights reserved 



\section{CUMULATIVE TRAUMA, EMOTION REACTIVITY AND SALIVARY CYTOKINE RESPONSE FOLLOWING ACUTE STRESS AMONG HEALTHY WOMEN}

By

Yvette Z. Szabo, M.A.

B.S., San José State University, 2012

M.A., University of Louisville, 2014

A Dissertation Approved on

May 4, 2017

By the following Dissertation Committee:

Dissertation Director: Dr. Tamara Newton

Dr. Rafael Fernandez-Botran

Dr. Rich Lewine

Dr. Sandra Sephton

Dr. Brendan Depue

ii 


\section{DEDICATION}

I would not be where I am today without the steadfast, unconditional support of my parents. They have provided different perspectives, both of which have made continuing education and moving so far from home possible. My mother has offered tireless encouragement, never doubting my aspirations. Though equally supportive, my father has always challenged me to think about how I could do better and be better. This is undoubtedly dedicated to them, and to my grandmother, whose greatest dream was that her grandchildren would earn $\mathrm{PhDs}$ and contribute to knowledge and learning. 


\section{ACKNOWLEDGEMENTS}

My graduate training, and this dissertation, was made possible by my mentor and

dissertation chair, Dr. Tamara Newton, who invited me into her lab. Through my doctoral training, I have grown tremendously as a researcher, writer, and thinker. I would like to thank her for her support and guidance, which have allowed me to shape my interests and build my identity as a researcher. I would also like to thank my dissertation committee, Drs. Fernandez-Botran, Lewine, Sephton and Depue, for their feedback related to my study and its contribution.

My sincere thanks are extended to everyone in the Stress \& Health Lab, including my labmate and peer mentor Kimberly Fleming, labmate Samantha Patton, and wonderful research assistants Rachael Parrill, Emily Schnider and Kandi Stinson. I would also like to express my gratitude to my friends and colleagues, particularly René BayleyVeloso for being my cheerleader and voice of reason for the last five years, Ashlee Warnecke for her unwavering support, pep talks and invaluable feedback and Frances Deavers for late night comradery during internship. Finally, I would like to thank my recreational sports teams because without lots of play, I would not have been able to accomplish so much work.

Finally, I would like to sincerely thank the women who participated in this study and the agencies which supported this research (see Appendix A). 


\begin{abstract}
CUMULATIVE TRAUMA, EMOTION REACTIVITY AND SALIVARY CYTOKINE RESPONSE FOLLOWING ACUTE STRESS AMONG HEALTHY WOMEN
\end{abstract}

\author{
Yvette Szabo, MA
}

May 4, 2017

This study furthers understanding of how trauma exposure may be connected to the development and maintenance of poor health by focusing on cytokines, tightly regulated proteins of the immune system. Cytokine responses to acute stress have been associated with the onset of poorer mental health in physically healthy women. The present study examined how two factors recently associated with cytokine reactivity cumulative trauma and emotion reactivity-are associated with salivary cytokine reactivity among healthy women. Seventy-one women, screened to be physically and mentally healthy, completed a laboratory acute stress paradigm and self-report measures of state emotion and trauma exposure. Participants were primarily White/EuropeanAmerican, with a mean age of 23 . The majority of participants reported experiencing at least one potentially traumatic event, with a mean of five. Saliva samples were taken 10 min before (i.e., baseline) and 35 min after the onset of a 10-min stressor, a modified version of the Trier Social Stress Test. State negative and positive emotion were measured at baseline and after the stressor. Cumulative trauma was not associated with 
changes in IL-1 $\beta$, IL-10 or IL1 $\beta /$ IL10 or changes in emotion. Declines in positive emotion correlated with increases in IL-1 $\beta$. Changes in both negative and positive emotion together were not related to cytokine responses. Given that this sample was healthy, despite high levels of trauma exposure, this may represent a resilient sample. Recommendations for future research are discussed, including measurement of trauma and of emotion. This study adds to the small but growing literature examining how trauma may connect to cytokines, and ultimately, the development and maintenance of poor health.

Keywords: cytokines, cumulative trauma, emotion reactivity, affect, anti-inflammatory 


\section{TABLE OF CONTENTS}

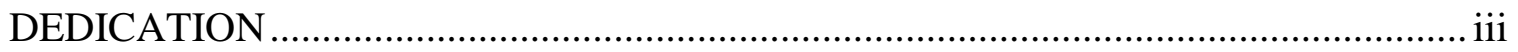

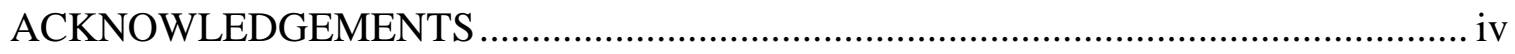

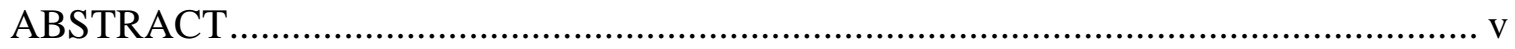

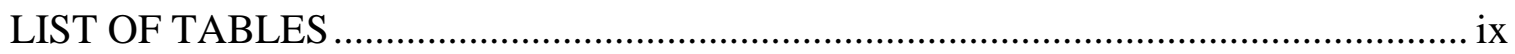

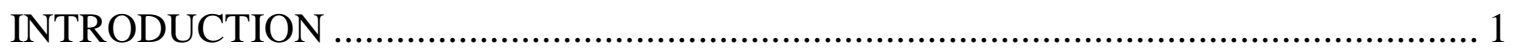

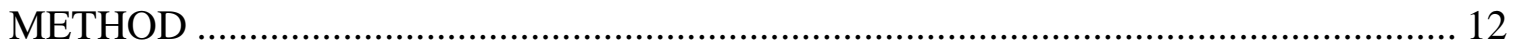

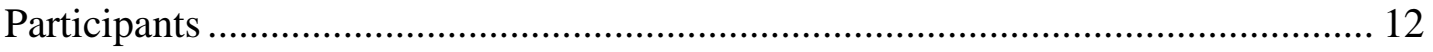

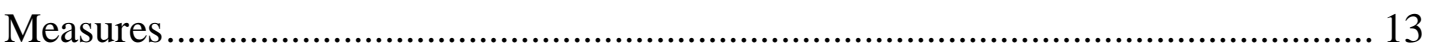

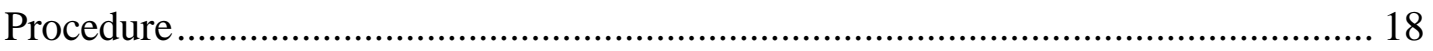

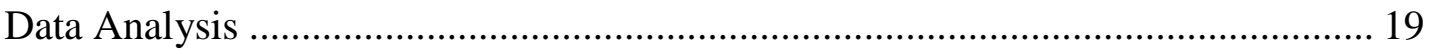

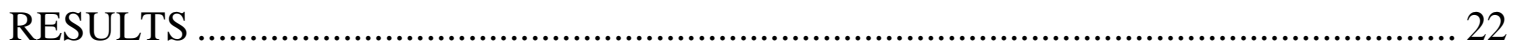

Aim 1: Cumulative Trauma and Cytokine Reactivity. ........................................ 29

Aim 2: Changes in State Emotion and Cytokine Reactivity............................... 31

Aim 3. Does Emotion Mediate Relationships Between Trauma and Cytokines? ... 33

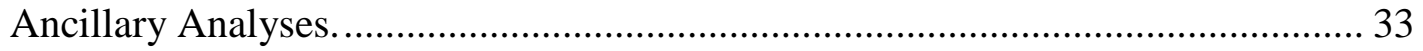


DISCUSSION

Implications and Future Directions ............................................................... 46

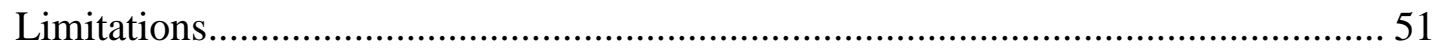

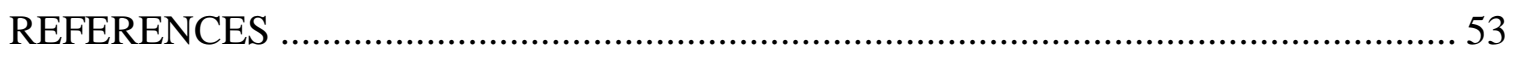

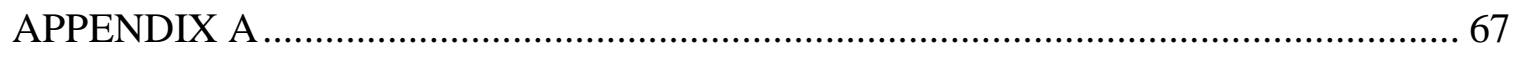

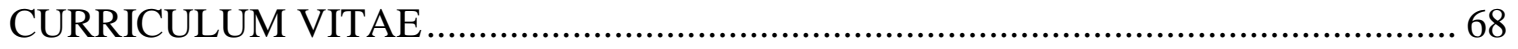

viii 


\section{LIST OF TABLES}

Table 1: Descriptive Statistics for Demographics and Health Characteristics

Table 2: Type of Trauma Exposure Reported

Table 3: Correlations Among Cumulative Trauma, State and Trait Emotion, and Cytokine Reactivity

Table 4: Linear Regression Models Predicting Cytokine Reactivity from Cumulative Trauma

Table 5: Linear Regression Models Predicting Cytokine Reactivity from Emotional

Reactivity 


\section{INTRODUCTION}

The top two leading causes of death for both men and women in the United States are heart disease and cancer-encompassing $48.1 \%$ and $43.9 \%$ of deaths, respectively (Centers for Disease Control and Prevention, 2013a; Centers for Disease Control and Prevention, 2013b). In addition, $18.5 \%$ of adults in the United States experience mental illness in a year, with one in five of those experiencing it to a degree that limits their everyday functioning (National Alliance of Mental Illness, 2016). Thus, many initiatives focus on increasing the understanding of determinants of disease in order to better design intervention and prevention. Importantly, exposure to traumatic events has been implicated in health problems. Further, many types physical and mental health problems have inflammatory correlates (e.g. Berg \& Scherer, 2005; Dowlati et al., 2010) and inflammation has been posited as one way in which exposure to trauma is linked to poor health outcomes (Kendall-Tackett, 2009). This study furthers the understanding of how trauma exposure may be connected to the development and maintenance of poor health by focusing on cumulative trauma exposure and a measure that has recently been shown to predict the development of poor mental health in physically healthy women - cytokine responses to acute stress (Aschbacher et al., 2012) - as measured in saliva.

Potentially traumatic events are defined as those that involve actual or perceived life threat, injury or sexual violence (American Psychiatric Association, 2013). Trauma exposure is prevalent and approximately three quarters of adults in Western countries 
reporting having been exposed to at least one potentially traumatic event in their lifetime (Roberts, Gilman, Breslau, Breslau, \& Koenen, 2011), with two-thirds of trauma-exposed persons experiencing multiple traumatic events, called cumulative trauma (Mills et al., 2011). The magnitude of associations between trauma exposure and both poorer mental and physical health is large (Scott et al., 2013; Tracy et al., 2014). For example, one study found that exposure to one traumatic event is associated with being 1.5 times more likely to have a chronic condition, with the odds increasing to 2.3 times with 5 or more exposures (Scott et al., 2013).

Associations between trauma and inflammation have been posited to be one way in which trauma exposure is linked to poor health (Kendall-Tackett, 2009). Inflammation is a biological cascade that aids the body in combatting infection and promoting healing from injury, which is regulated by proteins called cytokines. Cytokines are secreted by cells and tissues of the immune system, and signal the brain and other immune cells (Kronfol \& Remick, 2000). Cytokines can be detected in multiple bodily fluids, including urine, blood and oral fluids, such as saliva, and they can be quantified in multiple ways, including circulating levels, in-vitro stimulated responses, and reactions to acute stress. Pro-inflammatory cytokines, such as interleukin (IL)-1 $1 \beta$, increase the immune response to fight invading pathogens (Dinarello, 1988), while anti-inflammatory cytokines, such as IL-10, decrease cell function and the synthesis of other cytokines (Opal \& DePalo, 2000). As anti-inflammatory cytokines inhibit pro-inflammatory cytokine synthesis, the balance between the two classes of cytokines may also be an important consideration. Thus, some research further examines the ratio of pro- to anti-inflammatory cytokines as a measure of regulatory balance (Dhabhar et al., 2009; Remarque et al., 2001). In normal conditions, 
inflammation is tightly regulated; however, inflammation can become excessive, called a pro-inflammatory state, and can result in tissue damage (Dinarello, 2000). This has been associated with mental and physical health dysfunction, such as depression, diabetes and coronary heart disease (Dowlati et al., 2010; Luc et al., 2003).

Consistent with the idea that inflammation may connect trauma and health, many morbidities linked to trauma, such as depression, posttraumatic stress disorder (PTSD), arthritis, and cardiovascular disease, have been shown to have inflammatory bases (e.g. Dowlati et al., 2010; Luc et al., 2003). A meta-analysis of studies examining trauma exposure and circulating pro-inflammatory cytokines supported that trauma exposure is linked to increased IL-1 $\beta$, IL-6, and TNF- $\alpha$ (Tursich et al., 2014). However, few studies have examined the associations between trauma exposure and anti-inflammatory cytokines. One study found lower anti-inflammatory cytokines among trauma-exposed participants relative to a healthy comparison group without trauma exposure (Cohen et al., 2011). When cytokines were measured in vitro by stimulating peripheral blood mononuclear cells, recent sexual assault survivors displayed greater IL-10 and a lower IFN- $\gamma /$ IL10 ratio, indicating greater anti-inflammatory responses compared to healthy comparison participants (Groer, Thomas, Evans, Helton, \& Weldon, 2006).

In contrast to the fairly substantial literature on trauma and circulating cytokines, only four studies have examined trauma and cytokine reactivity to acute stress. Levels of many cytokines increase in response to acute stress (Steptoe, Hamer, \& Chida, 2007) and one study found that increases in serum IL- $1 \beta$, a pro-inflammatory cytokine, in response to acute stress predicted depression symptoms among physically healthy postmenopausal women at one year follow-up (Aschbacher et al., 2012). Such findings provide early 
evidence that pro-inflammatory cytokine reactivity to acute stress can have predictive validity for health.

Two studies examined the contribution of childhood trauma to cytokine responses using a standardized psychosocial stressor (Carpenter, Gawuga, Tyrka, Lee, \& Anderson, 2010; Pace et al., 2006). The results of the two studies suggest an increased plasma IL-6 response to stress in participants with histories of childhood trauma that may be heightened further by current syndromal depression. Further, amount of childhood trauma held a small to moderate relationship with IL-6 reactivity, though not statistically significant across the two studies. In a third study, women likely experiencing abuse and women not likely experiencing abuse read neutral scripts and scripts depicting abuse and then wrote about their own experiences in relationships (Danielson, Matheson, \& Anisman, 2011). There was no main effect of abuse status on post-task plasma IL-6 or IL-10 levels, and no interaction between condition and abuse status. However, IL-6 and IL-10 levels were highly, positively correlated in women without abuse histories, but not in women with abuse histories, suggesting that current abuse may alter regulation between pro- and anti-inflammatory cytokines. A final study was the only to use saliva to measure IL-1 $\beta$ in the context of trauma exposure (Tyrka, Parade, Valentine, Eslinger, \& Seifer, 2015). Among children, salivary IL-1 $\beta$ levels were positively correlated with four types of childhood trauma and maltreatment at baseline, but the magnitude of this correlation decreased following exposure to fear and frustration paradigms, suggesting children with recent trauma may demonstrate elevated pro-inflammatory status at baseline. 
Though the literature examining trauma and cytokine responses in the context of acute stress has examined recent trauma in both adults and children (Danielson et al., 2011; Tyrka et al., 2015) and childhood trauma in adult participants (Carpenter et al., 2010; Pace et al., 2006), no study has considered measures of cumulative trauma exposure across the lifespan. Three of the four studies examined quantity of trauma and associations with cytokines and found a positive linear relationship that varied in statistical significance, though this was only in one type of trauma - childhood maltreatment (Carpenter et al., 2010; Pace et al., 2006; Tyrka et al., 2015). Documented associations between trauma exposure and circulating inflammatory markers (Tursich et al., 2014) and cumulative trauma and chronic medical conditions (Scott et al., 2013) further emphasize that the absence of studies on cumulative trauma and cytokine responses to acute stress is an important gap in the literature that needs to be addressed. In addition, though only one study examined anti-inflammatory cytokines, it tentatively suggests comparable anti-inflammatory reactivity in trauma-exposed and non-traumaexposed persons, but a weaker relationship between pro- and anti- inflammatory cytokines, at least in the context of ongoing abuse (Danielson et al., 2011). In sum, it appears that trauma creates a vulnerability to altered inflammation, including in the context of acute stress, though questions remain about the specificity of this effect for various cytokines and the role of cumulative trauma exposure.

To date, research has not addressed potential mechanisms connecting trauma exposure and cytokine stress-reactivity, even though acute stress paradigms are wellsuited to elucidate the mechanisms and processes of stress-related changes. One possible mechanism may be through altered emotional responses to stress. Cognitive and affective 
appraisals of stressful situations have been theorized to precede peripheral physiological responses to stress (Tomaka, Blascovich, Kibler, \& Ernst, 1997), a hypothesis which has been recently extended to cytokine responses to stress. Emotions arise when an individual finds situational or goal-related meaning from a situation to which they are attending (Gross \& Thompson, 2007) and emotion reactivity refers to the degree of change in emotion in response to a stimulus. Negative and positive emotions may affect how we think about or interpret a stressor. Specifically, it is hypothesized that negative emotions lead to narrowing of attention to focus on potential threat, while positive emotions broaden focus and allow for the building of resources (Folkman \& Moskowitz, 2000). Consistent with the broaden-and-build theory of positive emotion (Fredrickson, 2001), one way that positive emotion may contribute to resilience following stress and trauma may be by affecting the degree of our physiological stress responses.

Emotion in the context of stress has been recently linked to cytokines following exposure to acute stress, though domain of emotion and measurement of stress-reactivity has varied across studies. Stress-related increases in anxiety and anger have been associated with IL-6 reactivity, but these associations were moderated by gender so that associations between anger and IL-6 were observed in men only (Carroll et al., 2011). Similarly, post-stressor fear has been linked to increased IL-6, accounting for baseline levels of emotion and IL-6 (Moons, Eisenberger, \& Taylor, 2010). Further, post-stressor anger, but not anxiety, was related to greater IL-6 reactivity in a sample of healthy postmenopausal women, though this was only found in women with low perceived social support (Puterman et al., 2014). One study examined IL-1 $\beta$ in oral mucosa transudate, an oral fluid, and found that post-stressor anxiety, but not anger, was associated with 
increased IL-1 $\beta$ accounting for baseline levels of emotion and IL-1 $\beta$ (Moons \& Shields, 2015). In the only study to examine general negative emotion and salivary cytokines, stress-related increases in negative emotion were linked to increases in salivary IL-1 $\beta$, IL-6 and TNF- $\alpha$ (Newton et al., in press). In terms of positive emotion, greater decreases in positive emotion following acute stress were associated with larger increases in IL-1 $\beta$ among healthy post-menopausal women (Aschbacher et al., 2012). However, it appears IL-6 stress-reactivity, which has been linked to increases in negative emotion following stress, does not hold these same relationships with positive emotion (Aschbacher et al., 2012; Carroll et al., 2011).

Together, it appears that some types of negative emotion are associated with increased pro-inflammatory cytokine responses to stress, though it is early to make definitive conclusions. Comparisons across studies are made difficult by discordant findings with different emotions, as well as a potential moderating effect of gender. Additionally, some studies used post-stressor levels of both emotion and cytokines, while others look at reactivity. Further, only two studies have examined IL-1 $\beta$, which has been linked to positive emotion while IL-6 has not. Anti-inflammatory cytokines as well as pro-/anti-inflammatory cytokine ratios remain understudied. Finally, no studies have measured both negative and positive emotion together, making it difficult to determine whether there is specificity in linkages between negative emotion, positive emotion, and cytokine reactivity to stress. Negative and positive emotions, though slightly correlated, are not bipolar opposites (Pressman \& Cohen, 2005); thus, the empirical investigation of both emotion types simultaneously in the context of cytokine reactivity is warranted. 
Trauma exposure has been linked to cytokine responses to acute stress, as have both negative and positive emotion. Whether stress-related changes in emotion might underlie associations between trauma and cytokine responses to stress has not yet been tested, however, related research supports this possibility. For example, greater cumulative childhood trauma was associated with greater negative emotional reactivity in adults, operationalized as a physician rating of apprehension to two injections (McLaughlin et al., 2010). Further, more major life events were associated with greater negative emotion and less positive emotion in response to daily life stressors among adults with histories of psychosis (Myin-Germeys, Krabbendam, Delespaul, \& van Os, 2004), though many of these events were not traumatic and included both negative and positive stress (e.g. marriage, work). More broadly, maltreated children exhibit greater activation of prefrontal cortex regions compared to non-maltreated children when regulating negative emotion, suggesting greater effort required to try to regulate emotion (McLaughlin, Peverill, Gold, Alves, \& Sheridan, 2015). This may be one potential way that effective regulation breaks down in the face of stressors, as this higher cognitive load may be difficult to maintain in the face of stress. Overall, the relationship between cumulative trauma and emotion reactivity warrants further attention as it is plausible that cumulative trauma is associated with positive and negative emotional reactions to stress, which in turn may be associated with cytokine responses to stress.

\section{Present Study}

This study used a laboratory-based paradigm to examine the contributions of trauma exposure and emotion reactivity to cytokine responses to acute stress, building on prior research in several ways. First, cumulative lifetime trauma exposure was measured. 
Second, both pro- and anti-inflammatory cytokines, as well as their relation to each other, were evaluated as measured in saliva. Whereas most studies reviewed here measured cytokines in blood, a growing literature has focused on salivary cytokines. Salivary cytokines are reactive to acute stress (Slavish et al., 2015) and have health-related validity given that they correlate with symptoms of trauma-related disorders in crosssectional studies (Newton, Fernandez-Botran, Miller \& Burns, 2014; Wang, Mandel, Levingston \& Young, 2016). However, they are not surrogates of cytokines measured in blood (Fernandez-Botran, Miller, Burns, \& Newton, 2011); thus, it is important to study how psychosocial factors correlate with cytokines in multiple fluids to understand relationships across these different regulatory systems. The present study selected IL-1 $\beta$ as a pro-inflammatory cytokine, as its reactivity has been shown to have predictive validity for mental health symptoms (Aschbacher et al., 2012), it has shown the greatest stress-reactivity in acute stress paradigms (Steptoe, Hamer, \& Chida, 2007) and it has been measured in saliva in relation to IL-10, a primary anti-inflammatory cytokine selected for measurement in this study (Szabo, Newton, Miller, Lyle \& FernandezBotran, 2016). Third, stress-related changes in both negative and positive emotion were measured to test their unique contributions to cytokine responses to acute stress. Further, follow-up analyses examined the role of trait affect. Trait measures of negative affect have been associated with increases in various measures of cytokines (Marsland, Prather, Petersen, Cohen, \& Manuck, 2008; Prather, Marsland, Muldoon, \& Manuck, 2007), including increases following acute emotional events (Brummett et al., 2010), but whether they account for the effects of stress-related increases in state emotion has not been examined. Fourth, strict inclusion criteria limited variability introduced due to 
chronic conditions or medication use. Finally, additional follow-up analyses examined how menstrual cycle phase and post-stressor thought (i.e. rumination, non-task related cognition) were related to cytokine reactivity as well as how state emotion changes over the course of the laboratory session, in response to stress and completing questions about traumatic and positive life events.

This study focused on women for several reasons. First, sex differences have been observed in some research on cytokines concentrations (Lynch, Dinarello, \& Cannon, 1994; Willis, Morris, Danis, \& Gallery, 2003) and women report greater increases in some negative emotions and greater decreases in happiness compared to men in response to the TSST (Kelly, Tyrka, Anderson, Price, \& Carpenter, 2008). In addition to this, women are exposed to fewer potentially traumatic events than men, but develop post-traumatic mental health problems at a greater rate than men (American Psychiatric Association, 2013). An index of stress that included both childhood and recent trauma correlated with mental and physical health more strongly for women than for men (Denton, Prus, \& Walters, 2004). Therefore, to reduce variability in the sample and to enhance generalizability for women's health, the study focused on women in order to further examine the interrelationship between constructs of interest with three primary aims.

The first aim was to examine associations between cumulative trauma and cytokine reactivity. We hypothesized that greater trauma exposure would be associated with greater increases in IL-1 $\beta$, smaller increases in IL-10, and a larger IL1 $\beta /$ IL10 cytokine ratio. The second aim was to identify the extent to which correlations between negative and positive emotional reactivity and cytokine reactivity are unique or 
independent in the context of acute stress, and which part of the cytokine regulatory network is related to emotional reactivity. We hypothesized that increases in negative emotion, but decreases in positive emotion, would independently be associated with increased IL-1 $\beta$, decreased IL-10, and a larger ratio IL1 $\beta / I L 10$ ratio. As a supplementary analysis, trait affect was examined in relation to cumulative trauma and changes in cytokines. A third aim was to determine whether stress-related changes in negative and positive emotion mediated associations between cumulative trauma and cytokine responses. 


\section{METHOD}

\section{Participants}

Sample and recruitment. Healthy women ages 18-40 were recruited from the University community. Advertisements on the online psychology participation management system included eligibility criteria and access for eligible participants to sign-up for a research visit. Additionally, community members were recruited with flyers posted around campus and brief advertisements distributed via listservs and word of mouth. Once interest was expressed, the investigator corresponded via email to provide eligibility criteria and allow members to sign-up for a research visit. Recruitment materials advertised for mentally and physically healthy women who are currently nonsmokers for a study on life experiences, emotion and stress. Participants recruited from the research pool received course credit for their participation $(n=46)$, while participants recruited using other means received no compensation $(n=7)$ or were entered into a lottery for one of two $\$ 50$ prepaid cards $(n=20)$. The study protocol was approved by the university's institutional review board and all participants provided informed consent.

Exclusion criteria. Participants were excluded from the study if they had a chronic medical condition (e.g., asthma, etc.) or a probable psychiatric condition (e.g., ADHD, depression, anxiety). Additionally, participants were not eligible if they were taking any medication (hormonal birth control was allowed) or were currently pregnant

or nursing. Further, participants were excluded if they had an oral health condition (i.e., 
gum disease, deep pockets, open sores), cavities or had an acute condition, such as a cold or recent injury.

Pre-visit restrictions. Due to the influence of several factors on cytokine concentrations and saliva samples, the investigator instructed participants to refrain from eating, brushing their teeth, exercising, and drinking anything besides water for one hour before the session.

\section{Measures}

Screeners. Participants completed a series of screeners to ensure they met eligibility criteria of being healthy and medication free. First, a series of "yes/no" questions assessed if participants had a chronic medical condition, oral health condition, psychiatric condition, were current smokers or took any medications. Then, additional "yes/no" questions assessed whether or not participants had violated any of the pre-visit restrictions.

Anxiety and depression. A four-item screener assessed symptoms of depression and anxiety in the past two weeks (Kroenke, Spitzer, Williams, \& Lowe, 2009). Each item, two inquiring about anxiety and two about depression, was rated on a scale of 0 "not at all" to 3 "nearly every day." A score of three or greater on the depression subscale had a sensitivity of .87 and a specificity of .78 to depression diagnosis as determined by structured clinical interview (Lowe, Kroenke, \& Grafe, 2005). While the original measure, developed in primary care, used a cut-off score of three or greater for the anxiety subscale (Kroenke, Spitzer, Williams, Monahan, \& Lowe, 2007), the present study used a cut-off score of five or greater as some studies have shown a higher cut-off 
on anxiety measures is needed in college student samples to identify potentially clinically relevant symptoms (Behar, Alcaine, Zuellig, \& Borkovec, 2003).

PTSD screener. A four item "yes/no" screener assessed for the presence of symptoms of PTSD in the past month (Prins et al., 2003). Developed for primary care, a score of 3 had a sensitivity of .78 and specificity of .87 when compared with diagnosis based on the Clinician Administered PTSD scale.

Oral health assessment. Three items assessed participants' periodontal health. One item asked about presence of dental caries: (1) No, I don't think so; (2) Yes, I have pain in teeth with hot/cold foods; (3) Yes, I have a huge cavity and toothache, and has a sensitivity of .85 and specificity of 1.0 for the presence of absence of dental caries upon clinical exam (Buhlin, Gustafsson, Andersson, Hakansson, \& Klinge, 2002). A second item asked about dentist diagnosis of deep pockets and had a sensitivity of .55 and specificity of .90 (Buhlin, Gustafsson, Andersson, Hakansson, \& Klinge, 2002). The final item asked about dentist diagnosis of periodontal or gum disease. This item had a sensitivity of .31 and specificity of .86 when indexed against moderate periodontal disease based on clinical exam and standard definitions of $\geq 2$ interproximal sites with clinical attachment levels of $\geq 4 \mathrm{~mm}$, or $\geq 2$ interproximal sites with probing depth of $\geq 5$ mm (LaMonte, Hovey, Millen, Genco, \& Wactawski-Wende, 2014).

Participant characteristics. Participants reported their date of birth, gender, ethnicity, and income. Participants reported the date of the first day of their last menstrual cycle and usual menstrual cycle length. This was used to calculate current menstrual cycle phase (follicular: days 1-14, luteal: days 15-33; Al-Harthi et al., 2000). The 
experimenter measured height (in inches) and weight (in pounds), which were used to calculate body mass index (BMI).

Cardiovascular Data. Systolic (SBP) and diastolic blood pressure (DBP) and heart rate (HR) were collected using a Dinamap 8100 monitor (Dinamap XL/Pro 100). Two ratings taken during the baseline phase and three ratings taken during the stressor phase, were averaged to form baseline and stress ratings, respectively.

Cumulative Trauma Measure. The 17-item Life Events Checklist assessed lifetime trauma exposure (Weathers et al., 2013). For each item, participants recorded whether an event had occurred or not, in each of six categories that applied (1=happened to me, 2=witnessed it, 3= learned about it, 4= part of my job, 5= not sure, $6=$ does not apply). Minor changes were made to the wording of the DSM-5 revision compared to the Life Events Checklist for DSM-IV and response option 4 was added (Weathers et al., 2013). The DSM-IV version has convergent validity with other established measures of trauma (Gray, Litz, Hsu, \& Lombardo, 2004). In the present study, it was unclear to participants that response 3 was only to be endorsed if the participant had learned the event had happened to a close family member or friend. Thus, for this study, a total score was calculated by counting the number of items endorsed as a 1, 2, or 4, consistent with DSM-5 definitions of potentially traumatic events (American Psychological Association, 2013). Potential scores ranged from 0-49 (two of the items cannot be endorsed as a 1 sudden violent death and sudden accidental death).

Biological Measures. Saliva was collected using plastic $2 \mathrm{~mL}$ cryovials and a small straw segment. Participants rinsed their mouth with water, swallowed to remove bacteria and food-related debris, and then waited 10 minutes before giving a sample to 
reduce the possibility of saliva dilution (Whembolua, Granger, Singer, Kivlighan, \& Marguin, 2006). Participants were instructed to pool saliva in their mouth for three minutes before gently forcing it into the cryovial through the straw segment. Samples were stored in a cooler with ice packs until the end of the session, then initially frozen at $20{ }^{\circ} \mathrm{C}$ and transferred to $-80^{\circ} \mathrm{C}$ for long-term storage. In preparation for assay, samples were thawed and centrifuged at $10,000 \mathrm{x}$ g for 10 minutes in order to remove insoluble material. The concentrations of IL-1 $\beta$ and IL-10 were measured using Milliplex MAP Human High Sensitivity T cell panel-Immunology Multiplex Assay kits (HSTCMAG28SK; EMD Millipore, Billerica, MA, USA) according to the manufacturer's instructions. Each sample was tested in duplicate. The minimum measurable concentrations (min DC) were $0.14 \mathrm{pg} / \mathrm{mL}$ and $0.56 \mathrm{pg} / \mathrm{mL}$ for IL-1 $\beta$ and IL-10, respectively. Intra- and inter-assay coefficients of variation (CV) were $<5 \%$ and $<15 \%$ for IL- $1 \beta$ and $<5 \%$ and $<20 \%$ for IL-10, respectively. Saliva flow rate $(\mathrm{mL} / \mathrm{min})$ was calculated by dividing the collected volume of saliva by three minutes. Flow rate adjusted cytokine levels were calculated by multiplying the cytokine concentration of the sample (in $\mathrm{pg} / \mathrm{mL}$ ) by the salivary flow rate (in $\mathrm{mL} / \mathrm{min}$ ), and are expressed as $\mathrm{pg} / \mathrm{min}$. Flow rates increased from baseline $(M=0.40, S D=0.28)$ to post stress $(M=0.47, S D=0.24), t(72)=$ $2.71, p=.01$.

State emotion. The state version of the 20-item Positive and Negative Affect Scale (PANAS) was used to measure state negative emotion (10 items) and positive emotion (10 items) (Watson, Clark, \& Tellegen, 1988). Each item is rated from $1=$ not at all to $5=$ extremely in response to how the participant feels "right now." Potential scores range from 10 to 50 for the negative and positive subscales. Internal consistency in the 
present study ranged from acceptable to excellent ( $\alpha=.75$ for negative emotion and $\alpha=.90$ for positive emotion at baseline; $\alpha=.91$ for negative emotion and $\alpha=.91$ for positive emotion post-stressor). For the measurement of emotion after the post-stressor rest period, after completion of the trauma measure, and after completion of the uplift scale, internal consistency was acceptable for negative emotion $(\alpha=.71-79)$ and excellent for positive emotion $(\alpha=.92-.93)$

Trait affect. The trait-version of the 20-item PANAS was used to measure negative (10 items) and positive affect (10 items; Watson et al., 1988). Each item was rated from $1=$ not at all to $5=$ extremely in response to how the participant generally feels. Potential scores range from 10 to 50 for each of the negative and positive subscales. Internal consistency in the present study was good to excellent ( $\alpha=.88$ for negative affect and $\alpha=.91$ for positive affect).

Post-stressor questions. Two questions assessed what participants thought about during the post-stressor period. An open-ended question asked participants to describe what they were thinking about. A second question asked participants to check all that are applicable to what they were thinking about: (1) the speech or math task, (2) current activities or things in the room (3) something completely different (Gerin, Davidson, Christenfeld, Goyal, \& Schwartz, 2006; Newton et al., in press). The open ended responses were used as a check for these categories. For the present study, this was scored as (1) thought about the task and (2) did not think about task at all, which served as a measure of rumination or non-task related cognition, respectively.

Positive events. The 43-item Positive Event Scale for University students (PESU) was used for participants to end the study on a positive note (Mayberry, 2013). 
Participants reported if each positive event occurred in the past month and, if so, how uplifting it was for them $(0=$ event did not occur to $5=$ event occurred and extremely uplifting). Potential scores ranged from 0-215 with larger scores indicating more uplift from positive events.

\section{Procedure}

All sessions were conducted between 12 and $5 \mathrm{pm}$ to control for diurnal variation in cytokine levels. Participants provided informed consent, then completed screeners that assessed eligibility. Responding participants that were recruited via online participation management systems but ineligible for the study were awarded 0.5 credit hours for their time; those recruited through any other mechanism but ineligible for the study received no compensation. Participants who were ineligible due to mental health symptoms were provided with a referral sheet (described below). Participants who violated the pre-visit restrictions were rescheduled for another session, and awarded 0.5 research credit hours for their time at this visit or received no compensation. Eligible participants completed questions about demographic information, menstrual cycle and trait affect. Then, participants rinsed their mouths and the experimenter fit the non-dominant arm with a blood pressure cuff. To establish an affective and cardiovascular baseline, participants were instructed to relax and count rectangles on a computer screen for eight minutes. Two blood pressure readings were taken during this phase, at four minutes and at seven minutes. Then, participants reported on baseline state emotion and provided the baseline saliva sample.

Acute Stressor. Following baseline, participants completed a 10-minute modified version of the TSST (Newton et al., in press), a standardized psychosocial 
stressor (Kirschbaum, Pirke, \& Hellhammer, 1993). The first part of the task is a speech participants had three minutes to make notes and prepare for a speech that explained why they were the best candidate for a job as a moderator of a focus group for college student issues. Then, participants imagined they were speaking with a selection committee, and gave a three minute speech into a video camera. If the participant paused for longer than 20 seconds, the experimenter prompted her to continue by asking her to further elaborate on her strengths and qualifications for the job. Following the speech, participants completed a mental arithmetic task. Participants counted backwards from 2083 by units of 13 for a total of 4 minutes. At standardized time points, participants were told to try to be accurate and to work more quickly to increase the evaluative component of the stressor. SBP, DBP and HR measurements were taken at minutes 3:30, 6:30 and 8:30.

Post-stressor. After completion of the TSST, participants provided their second state emotion rating, then were asked to sit quietly. After 35 minutes (45 minutes after the onset of the stressor), participants completed measures of state emotion and what they thought about during the post-stressor period. Then, participants provided a post-stressor saliva sample and completed measures of cumulative trauma, state emotion, past-month positive events, and state emotion, in that order. At the end of the post-stressor period, the experimenter measured the participant's height and weight and debriefed them. All participants who completed the study received a referral sheet for places to help reduce stress and improve mood (i.e. therapy services, tutoring center) in case of prolonged reactions to the stressor or recalling of traumatic exposures.

\section{Data Analysis}

Negative and positive emotions were totaled at each time point, and a change- 
score was calculated for state emotion by subtracting baseline values from post-stressor values. For participants with less than $25 \%$ of data missing at the scale level, affect data was imputed using the mean. For non-detectable cytokine values, the midpoint of 0 and the minimum detectable concentration was imputed ( 0.07 for IL-1 $\beta, n=7 ; 0.28$ for IL$10, n=1)$. Then, cytokine values were flow rate adjusted. To reduce skewness, the $\log 10$ transformation was applied to IL-1 $\beta$ and IL-10. The pro- to anti-inflammatory cytokine ratio at baseline and post-stressor was calculated from flow-rated adjusted levels then $\log 10$-transformed. Change scores for IL-1 $\beta$, IL-10, and IL1 $\beta /$ IL10 were created for each of the log10-transformed cytokine levels by subtracting baseline values from poststressor values. Change-scores for state positive emotion and levels of trait positive affect were normally distributed. Trait negative affect was $\log 10$ transformed to reduce positive skewness. The change score for state negative emotion was slightly positively skewed, but not log- transformed for analysis in order to simplify interpretation relative to state positive emotion.

Correlations for normally distributed variables used Pearson correlations, while variables that were not normally distributed used the non-parametric alternative, Spearman's rank correlations. For all regression analyses, assumptions for parametric tests were assessed. First, linearity of predictors was assessed and residual plots were inspected for potential evidence of a curvilinear relationship. Homoscedasticity of residuals was assessed by visual inspection of plots of the standardized residual by the predicted value.

Hormonal birth control use (yes coded as ' 0 ', and no coded as ' 1 ') and BMI (continuous) were selected as a priori covariates for models using cytokines based on 
their relationship with cytokines in past literature and recommendations for their consideration with salivary cytokines (Slavish et al., 2015). Analyses were conducted using SAS statistical software 9.6. The criterion for statistical significance was $\alpha=.05$. A priori power analyses using $\mathrm{G}^{*}$ Power statistical software (Faul, Erdfelder, Lang, \& Buchner, 2007) for multiple linear regression indicated 42-70 individuals were needed to detect effects typical of those found in the literature for each aim. 


\section{RESULTS}

One hundred and five participants enrolled into the study. Some enrolled participants were ineligible due to potentially clinically meaningful mental health symptoms ( $n=9$ for PTSD, $n=2$ for anxiety, $n=3$ for more than one positive mental health screen); others were ineligible due to taking medication $(n=3)$, being diagnosed with a psychiatric disorder $(n=2)$, being a current smoker $(n=1)$ or having an oral health condition $(n=4)$. Six women were ineligible in more than one category (i.e. having both an oral health condition and PTSD). One participant violated pre-visit restrictions but declined to reschedule, and one participant discontinued the study prior to completing it. Seventy-three participants completed the study protocol. Two participants were missing state emotion data due to technical errors and removed from analysis. Thus, 71 participants with complete data for the primary variables of interest are included here.

Study Sample Characteristics. All participants identified both their sex and gender as female. As shown in Table 1, the average age was 23 years, and most participants self-identified as European American/White. About half reported an annual household income of less than $\$ 40,000$. About sixty percent currently used hormonal contraceptives. Average BMI was in the normal range. Overall, mental health symptoms were low, suggesting the participants were mentally healthy. Trait affect was slightly lower than other samples for negative affect but comparable for positive affect (Watson et al., 1988). 


\section{Table 1}

Descriptive Statistics for Demographics and Health Characteristics

Demographic or Characteristic Mean (SD) or \% of sample (n)

Age (in years)

$22.88(3.76)$

Ethnicity

European American or White

$71.01 \%(49)$

African American or Black

$8.70 \%(6)$

Asian American

$1.45 \%(1)$

Latino or Hispanic American

$7.25 \%(5)$

Native American or Alaskan Native

$0 \%$

Biracial or multiethnic

$7.25 \%(5)$

Other

$4.35 \%(3)$

Annual Household Income

0-9, 9999

$14.49 \%(10)$

$10,000-19,999$

$8.70 \%(6)$

$20,000-29,999$

$15.94 \%(11)$

$30,000-39,999$

$14.49 \%(10)$

$40,000-49,999$

$11.59 \%$ (8)

$50,000-59,999$

$4.35 \%(3)$

60,000 or above

$30.43 \%(21)$

Body Mass Index

$25.56(5.42)$ 
Hormonal Contraceptive Use

Yes

$60.87 \%(42)$

No

$39.13 \%(27)$

Menstrual Cycle Phase

Follicular

Luteal

Trait Negative Affect

Trait Positive Affect

PTSD symptoms

$0.23(0.51) \gamma$

Depression screener

Anxiety screener

$0.83(0.96)$

Note. $\mathrm{N}=71$ except for ethnicity, income, and contraceptive use $(\mathrm{N}=69)$ and menstrual cycle phase ( $\mathrm{N}=55$ due to missing data and atypical cycle lengths)

${ }^{\gamma} \mathrm{M}$ and SD are presented in the table, but this measure is significantly skewed. For comparison purposes, the median for trait negative affect is 14 (interquartile range $=7$ ). The median is for PTSD symptoms is 0 (interquartile range $=0$ ).

Most women reported experiencing at least one traumatic event $(n=69 ; 97.18 \%)$;

Table 2 provides the list of events reported. This is greater prevalence than another study that surveyed college students from a midwestern university (66.5\%; Elhai et al., 2012) as well as a study that used the DSM-IV version of the trauma measure and recruitment ads similar to those used in the present study (80\%; Gibson et al., 2014). Participants with trauma exposure were evenly distributed in terms of the number of exposures $(1,2,3$, and 4+ events, each about $20 \%$ of the total sample; Gibson et al., 2014). 


\section{Table 2}

Type of Trauma Exposure Reported

\begin{tabular}{|c|c|c|c|}
\hline Type of Trauma & Happened to me & Witnessed it & Part of my job \\
\hline Natural Disaster & $30.99 \%$ & $26.76 \%$ & $1.41 \%$ \\
\hline Fire or Explosion & $4.23 \%$ & $14.08 \%$ & $1.41 \%$ \\
\hline Transportation accident & $54.93 \%$ & $43.66 \%$ & $0.00 \%$ \\
\hline Serious accident at work, home & $9.09 \%$ & $25.76 \%$ & $0.00 \%$ \\
\hline \multicolumn{4}{|l|}{ or during recreation } \\
\hline Exposure to toxic substance & $1.41 \%$ & $2.82 \%$ & $4.23 \%$ \\
\hline Physical assault & $18.57 \%$ & $28.57 \%$ & $1.41 \%$ \\
\hline Assault with a weapon & $1.41 \%$ & $2.82 \%$ & $2.82 \%$ \\
\hline Sexual assault & $19.72 \%$ & $2.82 \%$ & $1.41 \%$ \\
\hline Other unwanted or & $38.03 \%$ & $5.63 \%$ & $1.41 \%$ \\
\hline \multicolumn{4}{|l|}{ uncomfortable sexual } \\
\hline \multicolumn{4}{|l|}{ experience } \\
\hline Combat or exposure to a war- & $1.41 \%$ & $1.41 \%$ & $1.41 \%$ \\
\hline \multicolumn{4}{|l|}{ zone } \\
\hline Captivity & $1.41 \%$ & $1.41 \%$ & $0.00 \%$ \\
\hline Life-threatening illness or & $12.68 \%$ & $49.30 \%$ & $2.82 \%$ \\
\hline \multicolumn{4}{|l|}{ injury } \\
\hline Severe human suffering & $0.00 \%$ & $22.54 \%$ & $5.63 \%$ \\
\hline Sudden violent death & $0 \%$ & $9.86 \%$ & $4.23 \%$ \\
\hline
\end{tabular}


Sudden accidental death

Serious injury, harm or death

you caused to someone else

Any other very stressful event

or experience
$0 \%$

$2.86 \%$

$37.14 \%$

$14.29 \%$

$2.86 \%$

Levels of salivary IL-1 $\beta$ and IL-10 at baseline were lower (IL- $1 \beta$ median $=0.72$ $\mathrm{pg} / \mathrm{mL}, \mathrm{IQR}=1.99 \mathrm{pg} / \mathrm{mL} ; \mathrm{IL}-10$ median $=1.32 \mathrm{pg} / \mathrm{mL}, \mathrm{IQR}=1.16 \mathrm{pg} / \mathrm{mL})$ than those in a mixed gender sample $(\mathrm{IL}-1 \beta$ median $=7.74 \mathrm{pg} / \mathrm{mL}, \mathrm{IQR}=5.17 \mathrm{pg} / \mathrm{mL} ; \mathrm{IL}-10$ Median $=$ $4.86 \mathrm{pg} / \mathrm{mL}, \mathrm{IQR}=7.50 \mathrm{pg} / \mathrm{mL}$; Szabo et al., 2016). Similarly, levels of salivary IL-1 $\beta$ and IL-10 post-stress were lower (IL-1 $\beta$ median $=1.16 \mathrm{pg} / \mathrm{mL}, \mathrm{IQR}=4.22 \mathrm{pg} / \mathrm{mL}$; IL-10 median $=1.92 \mathrm{pg} / \mathrm{mL}, \mathrm{IQR}=2.21 \mathrm{pg} / \mathrm{mL}$ ) than those in this mixed-gender sample that completed the same modified stressor $(\mathrm{IL}-1 \beta$ median $=4.86 \mathrm{pg} / \mathrm{mL}, \mathrm{IQR}=7.50 \mathrm{pg} / \mathrm{mL}$; $\mathrm{IL}-10$ median $=6.96 \mathrm{pg} / \mathrm{mL}, \mathrm{IQR}=12.47 \mathrm{pg} / \mathrm{mL})$. The ratio of IL1 $\beta / \mathrm{IL} 10$ showed considerable variability at both baseline $($ Median $=0.54, \mathrm{IQR}=3.57)$ and post-stress $($ median $=0.72, \mathrm{IQR}=3.76)$.

Mean state emotion at baseline $(M=12.02, S D=2.70$ and $M=24.54, S D=8.43$ for negative emotion and positive emotion, respectively) was similar for negative emotion but lower for positive emotion compared to other samples of similarly aged adults completing the TSST (Pabst, Brand, \& Wolf, 2013) as well as students in the initial validation studies (Watson, Clark, \& Tellegen, 1988). Mean state emotion at poststress $(M=18.75, S D=7.73$ and $M=21.30, S D=8.17$ for negative emotion and positive emotion, respectively) was comparable to that of other samples of similarly aged adults 
completing the TSST for negative emotion but lower for positive emotion (Pabst et al., 2013).

Manipulation Check. Statistically significant paired t-tests comparing baseline and post-stressor $\operatorname{SBP}(t(69)=12.24, p<.001, d=1.47), \mathrm{DBP}(t(69)=14.06, p<.001, d$ $=1.69)$ and HR $(t(69)=9.59, p<.001, d=1.15)$ showed that the stressor was successful in inducing physiological arousal.

Cytokine and Emotional Reactivity. Both IL-1 $\beta$ and IL-10 increased in response to the TSST, IL-1 $\beta, t(70)=5.28, p<.001, d=0.63$ and IL-10, $t(70)=6.13, p$ $<.001, d=0.73$. The ratio of IL1 $\beta /$ IL10 did not show statistically significant change from baseline to post-stress, $t(70)=0.69, p=.49, d=0.08$. Despite this lack of uniform change in the ratio, there was considerable variability, suggesting that individuals differ markedly in balance between pro- and anti-inflammatory cytokines in response to the task. Thus, analyses to examine correlates of this variability were conducted as planned. Negative emotion increased in response to the stressor, $t(70)=7.87, p<.001, d=1.05$. Positive emotion decreased in response to the stressor, $t(70)=-4.51, p<.001, d=-0.39$. Means and standard deviations for and correlations between the primary variables of interest are shown in Table 3. 


\section{Table 3}

Correlations Among Cumulative Trauma, State and Trait Emotion, and Cytokine Reactivity

\begin{tabular}{|c|c|c|c|c|c|c|c|c|}
\hline & $\mathrm{M}(\mathrm{SD})$ & 2 & 3 & 4 & 5 & 6 & 7 & 8 \\
\hline 1. Cumulative Trauma & $5.38(3.60)$ & .06 & -.04 & .19 & -.02 & .01 & -.19 & .14 \\
\hline 2. Trait Positive Emotion & $34.15(7.89)$ & -- & .13 & -.05 & -.10 & .04 & .01 & .03 \\
\hline 3. Trait Negative Emotion & $15.69(5.33)$ & & -- & .01 & $.28 *$ & $<.01$ & .07 & -.05 \\
\hline 4. $\Delta$ Positive Emotion & $-3.24(6.06)$ & & & -- & -.17 & $-.23^{*}$ & -.12 & -.15 \\
\hline 5. $\Delta$ Negative Emotion & $6.74(7.22)$ & & & & -- & .13 & .06 & .08 \\
\hline 6. $\Delta$ IL-1 $\beta$ & $0.38(0.61)$ & & & & & -- & $.44 * * *$ & $.70 * * *$ \\
\hline 7. $\Delta$ IL-10 & $0.33(0.46)$ & & & & & & -- & $-.33 * *$ \\
\hline 8. $\Delta \mathrm{IL}-1 \beta / \mathrm{IL}-10$ & $0.05(0.57)$ & & & & & & & -- \\
\hline
\end{tabular}

Note. $*<.05, * *<.01, * * *<.001 . \mathrm{N}=71$, except for Trait Positive Affect and Trait Negative Affect where $\mathrm{N}=69$

Pearson correlations are reported for cumulative trauma, trait positive emotion, change in positive emotion, IL-1 $\beta$, IL-10 and the IL-1 $\beta /$ IL-10, as both variables were normally distributed. Change in negative emotion and trait negative emotion were significantly skewed and thus, Spearman Rho is reported for relationships with these variables.

$\Delta=$ (post-stressor - baseline) 
Aim 1: Cumulative Trauma and Cytokine Reactivity. Three separate linear regressions examined the extent to which cumulative trauma exposure is associated with cytokine reactivity to acute stress (Table 4). Cumulative trauma was not significantly associated with $\Delta \mathrm{IL}-1 \beta(\beta=0.01, p=.93), \Delta \mathrm{IL}-10(\beta=-0.19, p=.12)$ or $\Delta \operatorname{IL} 1 \beta / \operatorname{IL} 10(\beta$ $=0.14, p=.25)$. After adjusting for covariates, the patterns of findings were unchanged (all $F s<1.36, p s \geq .26$ ). In all adjusted models, neither BMI nor hormonal contraceptive use were statistically significant. 


\section{Table 4}

Linear Regression Models Predicting Cytokine Reactivity from Cumulative Trauma

\begin{tabular}{|c|c|c|c|c|c|c|c|c|c|c|c|c|}
\hline & \multicolumn{4}{|c|}{$\Delta \mathrm{IL}-1 \beta$} & \multicolumn{4}{|c|}{$\Delta \mathrm{IL}-10$} & \multicolumn{4}{|c|}{$\Delta \mathrm{IL}-1 \beta / \mathrm{IL}-10$} \\
\hline Predictor & $R^{2}$ & $B$ & $\mathrm{SE}$ & $\beta$ & $\Delta R^{2}$ & $B$ & $\mathrm{SE}$ & $\beta$ & $\Delta R^{2}$ & $B$ & $\mathrm{SE}$ & $\beta$ \\
\hline \multicolumn{13}{|c|}{ unadjusted } \\
\hline Cumulative Trauma & $<.01$ & $<-.01$ & .02 & -.01 & .02 & .02 & $<.01$ & -.19 & .02 & .02 & .02 & .14 \\
\hline \multicolumn{13}{|c|}{ adjusted } \\
\hline Cumulative Trauma & $<.01$ & $<.01$ & .02 & $<.01$ & .02 & -.02 & .02 & -.16 & .02 & .02 & .02 & .13 \\
\hline BMI & & -.01 & .01 & -.13 & & $<.01$ & .01 & -.06 & & $<.01$ & .01 & -.09 \\
\hline Contraceptive Use & & .19 & .15 & .15 & & .14 & .11 & .16 & & .04 & .15 & .04 \\
\hline
\end{tabular}

Note. $*<.05, * *<.01, * * *<.001$. Adjusted for body mass index and hormonal contraceptive use. BMI $=$ body mass index. $\Delta$ IL-1 $\beta$ (unadjusted; $\mathrm{n}=71$ ): $R^{2}<.01, F(1,69)=.01, p=.93, \Delta$ IL-1 $\beta$ (adjusted; $\mathrm{n}=69$ ): $R^{2}=.04, F(3,65)=82, p=.49$. $\Delta$ IL-10 (unadjusted; $\mathrm{n}=71$ ): $R^{2}=.04, F(1,69)=2.47, p=.12, \Delta$ IL-10 (adjusted; $\left.\mathrm{n}=69\right): R^{2}=.06, F(3,65)=1.35, p=.26$. $\Delta$ IL1 $\beta /$ IL10 (unadjusted; $\mathrm{n}=71): R^{2}=.02, F(1,69)=1.33, p=.25, \Delta$ IL1 $\beta /$ IL10 (adjusted; $\left.\mathrm{n}=69\right): R^{2}=.03, F(3,65)=.58$, $p=.63$. 
Aim 2: Changes in State Emotion and Cytokine Reactivity. As shown in Table 3 , a significant correlation was observed between increased $\Delta \mathrm{IL}-1 \beta$ and decreases in positive emotion $(p<.05)$. No other significant zero-order correlations were observed between changes in positive emotion, changes in negative emotion and $\Delta \mathrm{IL}-1 \beta, \Delta \mathrm{IL}-10$ and $\Delta$ IL1 $\beta /$ IL10. As shown in Table 5 , the set of emotion change scores was not significantly associated with $\Delta \mathrm{IL}-1 \beta\left(R^{2}=.06, p=.14\right)$, though positive emotion was marginally associated with $\Delta \mathrm{IL}-1 \beta(\beta=-0.23, p=.06)$. After adjusting for covariates, the model was not statistically significant but positive emotion contributed unique variance to the model, $F(1,64)=4.10, p<.05$. The set was not significantly associated with $\Delta \mathrm{IL}-$ $10\left(R^{2}\right.$ change $\left.=.05, p=.51\right)$ or $\Delta \mathrm{IL} 1 \beta / \mathrm{IL} 10\left(R^{2}\right.$ change $\left.=.025, p=.43\right)$. Both models were unchanged after adjusting for covariates. In all adjusted models, neither BMI nor contraceptive use were statistically significant. Thus, only changes in positive emotion were associated with $\Delta \mathrm{IL}-1 \beta$.

Aim 2b. Trait Affect and Cytokine Responses. As shown in Table 3, trait negative affect was positively correlated with changes in negative emotion, but a relationship was not observed between trait positive affect and changes in positive emotion. Trait negative affect was not significantly associated with $\Delta \mathrm{IL}-1 \beta, \Delta \mathrm{IL}-10$ and $\Delta \mathrm{IL} 1 \beta / \mathrm{IL} 10$ and results were unchanged after adjusting for covariates (all $F \mathrm{~s}<1.00, p \mathrm{~s} \geq$ .47). Trait positive affect was not significantly associated with $\Delta \mathrm{IL}-1 \beta, \Delta \mathrm{IL}-10$ and $\Delta \mathrm{IL}-$ $1 \beta / \mathrm{IL}-10$ and results were unchanged after adjusting for covariates (all $F \mathrm{~s}<1.00, p \mathrm{~s} \geq$ .47). This suggests trait affect was unrelated to changes in cytokines, and that associations between changes in state positive emotion and $\Delta \mathrm{IL}-1 \beta$ do not reflect associations between trait affect and $\Delta \mathrm{IL}-1 \beta$. 
Table 5

Linear Regression Models Predicting Cytokine Reactivity from Emotional Reactivity

$\Delta \mathrm{IL}-1 \beta \quad \Delta \mathrm{IL}-10 \quad \Delta \mathrm{IL}-1 \beta / \mathrm{IL}-10$

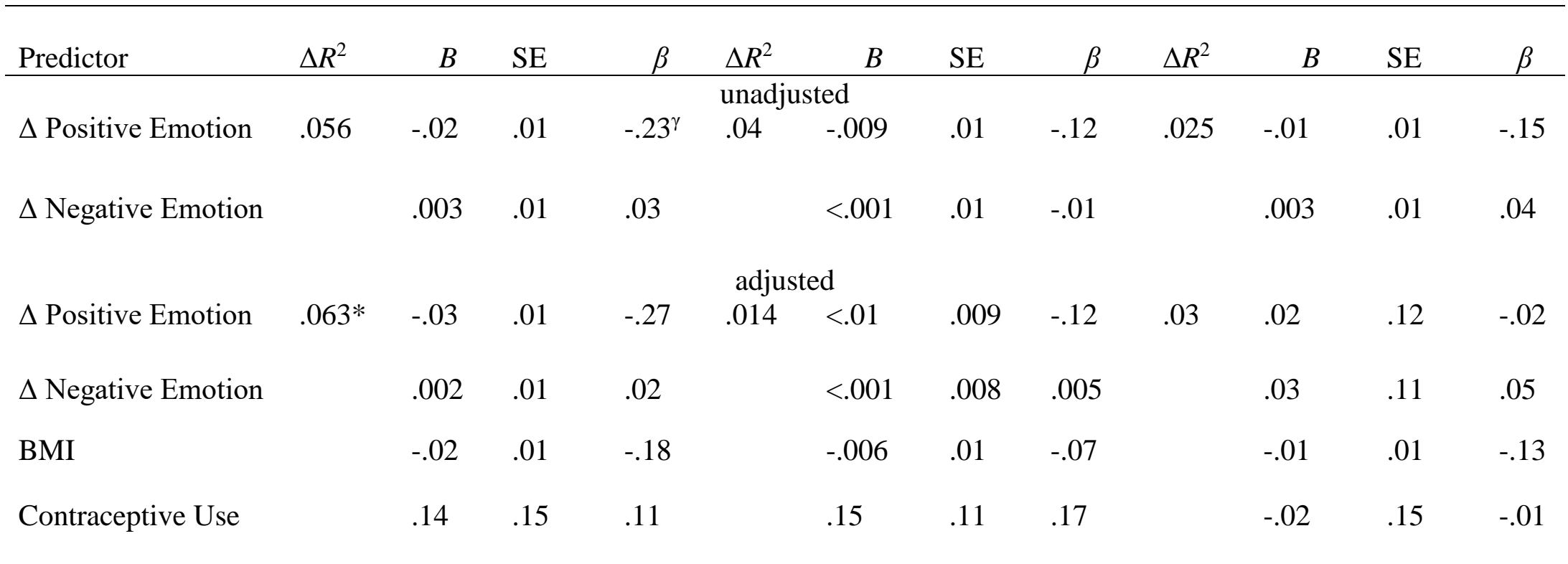

Note. ${ }^{\gamma}<.10, *<.05, * *<.01, * * *<.001$. Adjusted for body mass index and hormonal contraceptive use. BMI $=$ body mass index.

$\Delta \mathrm{IL}-1 \beta$ (unadjusted; $\mathrm{n}=71): R^{2}=.056, F(2,68)=2.02, p=.14, \Delta \mathrm{IL} 1 \beta$ (adjusted; $\mathrm{n}=69$ ): $R^{2}=.10, F(4,64)=1.76, p=.15$. $\Delta \mathrm{IL}-10$ (unadjusted; $\mathrm{n}=71): R^{2}=.043, F(2,68)=.50, p=.61, \Delta \mathrm{IL} 10($ adjusted; $\mathrm{n}=69): R^{2}=.05, F(4,64)=.84, p=.51$.

$\Delta \mathrm{IL1} \beta / \mathrm{IL} 10$ (unadjusted; $\mathrm{n}=71): R^{2}=.025, F(2,68)=.86, p=.43, \Delta \mathrm{IL} 1 \beta / \mathrm{IL} 10($ adjusted; $\mathrm{n}=69): R^{2}=.04, F(4,64)=.67, p$ $=.62$.

$\Delta R^{2}$ refers to the change for the set of two state emotion variables 


\section{Aim 3. Does Emotion Mediate Relationships Between Trauma and}

\section{Cytokines?}

Cumulative trauma was not significantly associated with change in negative emotion $(F(1,69)=0.06, p=.81, \beta=-0.02)$ or change in positive emotion $(F(1,69)=$ $2.52, p=.12, \beta=0.19)$ in response to the stressor. Thus, cumulative trauma is not related to the proposed mediators, changes in emotion, and mediation cannot be assessed.

\section{Ancillary Analyses.}

Cumulative Trauma and Trait Affect. Cumulative trauma was not significantly related to trait negative $(r(69)=-.06, p=.60)$ or trait positive affect $(r(69)=-.13, p=$ $.33)$.

Post-stressor rumination. Thirty-seven women reported thinking about the stressor during the post-stressor period (rumination) and 29 reported thinking only about things in the room or something else (non-task related cognition). Three separate logistic regression models were used to test associations between cumulative trauma, negative emotion reactivity, positive emotion reactivity, and post-stressor rumination. Cumulative trauma was significantly negatively associated with the likelihood of engaging in post-

stress rumination, Wald's $\chi^{2}(65)=3.95, p<.05, \beta=-0.30, p<.05, \mathrm{OR}=0.86$. For each additional trauma the participant was exposed to, they were $14 \%$ less likely to have ruminated during the post-stressor period. Changes in negative emotion did not predict likelihood of engaging in post-stressor rumination, Wald's $\chi^{2}(65)=1.95, p=.16, \beta=$ $0.21, p=.16$. However, changes in positive emotion were significantly, negatively associated with likelihood to ruminate, Wald's $\chi^{2}(65)=3.86, p<.05, \beta=-0.30, p<.05$, 
$\mathrm{OR}=0.91$. For each one-unit decline in positive emotion from baseline to post-stressor, participants were $9 \%$ more likely to have ruminated. When the emotion variables were added as a set, the model was only marginally significant, $\chi^{2}(65)=5.41, p=.07$. Negative emotion did not predict rumination and positive emotion was only marginally significant $(\beta=-0.29, p=.06)$. Simple linear regression models showed that post-stressor rumination was not significantly associated with $\Delta \mathrm{IL}-1 \beta(\beta=0.11, p=.38), \Delta \mathrm{IL}-10(\beta=$ $0.05, p=.68)$ or $\Delta \mathrm{IL}-1 \beta / \mathrm{IL}-10(\beta=0.16, p=.21$; all $F \mathrm{~s} \leq 1.60, p \geq .21)$.

Menstrual cycle variables. An additional follow-up analysis considered both menstrual cycle phase and hormonal contraceptive use in association with each of the cytokines. Using linear regression and dummy coded variables, women were classified into one of three groups (luteal $n=17$, follicular $n=6$, hormonal contraceptives $n=42$ ). Menstrual cycle was marginally associated with $\Delta \mathrm{IL}-1 \beta, F(2,68)=2.44, p<.10$ and $\Delta \mathrm{IL}-10, F(2,68)=2.44, p<.10$. In both models, participants in the luteal phase of the menstrual cycle tended to demonstrate greater changes in cytokines compared to those on hormonal contraceptives (both models $\beta=.31, p=.06$ ), whom did not differ from those in the follicular phase $(p s>.11)$. Menstrual cycle was not significantly associated with the $\Delta \mathrm{IL} 1 \beta / \mathrm{IL} 10$ ratio, $F(2,68)=0.15, p=.86$.

Emotion Over Time. A repeated measures analysis of variance (ANOVA) examined emotion over the course of the session (baseline, post-stressor, post-stressor rest, post-trauma measure, post-uplift measure). The Greenhouse-Geisser correction for violation of sphericity was used. Follow-up pairwise comparisons were corrected using a Bonferroni adjusted alpha level of .005 to account for multiple comparisons. There was a statistically significant main effect of time for negative emotion, $F(1.31,21.89)=63.83$, 
$p<.001$. Negative emotion increased significantly from baseline to post-stressor, $t(70)=$ 7.87, $p<.001$, but decreased during the post-stressor rest period, $t(70)=-8.23, p<.001$, such that levels were comparable to baseline levels, $t(70)=1.68, p<.10$. Negative emotion did not change from the end of the post-stressor rest period to post-trauma measure, $t(70)=-0.46, p=.65$, nor in response to the uplift scale compared to the posttrauma measure, $t(70)=-2.30, p=.02$. When comparing post-stressor rest period to postuplift measure, there was no difference in negative emotion, $t(70)=1.50, p=.14$, though negative emotion had decreased from baseline to post uplift scale, $t(70)=-3.42, p<.001$.

Similarly, there was a statistically significant main effect of time for positive emotion, $F(3.39,56.86)=21.05, p<.001$. Positive emotion decreased from baseline to post-stress $(t(70)=-4.51, p<.001)$ and continued to decline during the post-stressor period $(t(70)=-3.50, p<.001)$, so that positive emotion was significantly lower following the post-stressor rest period compared to baseline, $t(70)=-9.50, p<.001$. Positive emotion increased from the post-stressor rest period to after the trauma measure, $t(70)=5.44, p<.001$ and but did not change following the positive uplift scale compared to after the trauma measure, $t(70)=1.87, p=.07$. Positive emotion was significantly higher after the uplift scale than after the post-stressor rest period, $t(70)=$ 6.21, $p<.001$, though lower after the uplift scale compared to baseline $(t(70)=-2.70, p$ $<.001)$.

Direct Trauma Exposure. A final set of follow-up analyses was conducted to integrate this study with prior literature examining cumulative trauma and cytokine reactivity. Many other studies measured trauma that was directly experienced by the participant. Thus, primary analyses were rerun with a measure of direct trauma exposure, 
measured as a count of events endorsed as "happened to me" $(M=2.32, S D=1.71)$. The pattern of findings did not change for relationships with $\Delta \mathrm{IL}-1 \beta(\beta=-.05, p=.65)$ or $\Delta \operatorname{IL1} \beta / \operatorname{IL10}(\beta=.12, p=.30)$, though the relationship between cumulative trauma and $\Delta \mathrm{IL}-10$ approached statistical significance $(F(1,69)=3.85, p=.05 ; \beta=-.23, p=.05)$. This relationship was attenuated slightly when adjusting for covariates, though it was no longer marginally significant, $F(3,65)=1.69, p=.18 ; \beta=-.20, p=.11$. Direct trauma exposure did not predict changes in negative emotion $(\beta=-.09, p=.44)$ or changes in positive emotion $(\beta=-.17, p=.15)$, and the relationship with likelihood of engaging in post-task rumination was no longer observed, Wald's $\chi^{2}(65)=.51, p=.48$. Thus, the pattern of findings was largely unchanged, though the relationship with $\Delta \mathrm{IL}-10$ was strengthened and the relationship with likelihood to ruminate was no longer observed. 


\section{DISCUSSION}

To further understand how trauma exposure is linked to mental and physical health, the present study investigated how cumulative trauma and stress-related changes in negative and positive emotion were associated with salivary cytokine reactivity to acute stress among healthy women. Manipulation checks for this study demonstrated increases in SBP, DBP and HR that were large in magnitude, suggesting that the stressor was successful in inducing a physiological reaction. Both IL-1 $\beta$ and IL-10 increased in response to the stressor, demonstrating reactivity that was moderate in magnitude. While the ratio did not demonstrate a main effect of stress, there was considerable variability, with some participants shifting to a pro-inflammatory profile, some remaining balanced, and others shifting to an anti-inflammatory profile. Further, negative emotion showed large stress-related increases, while positive emotion decreased a small amount in response to stress. Trauma exposure was prevalent, with a mean of five exposures reported.

The main findings of this study were that cumulative trauma was not associated with increases in $\Delta \mathrm{IL}-1 \beta, \Delta \mathrm{IL}-10$, or the $\Delta \mathrm{IL}-1 \beta / \mathrm{IL}-10$ ratio in this sample of healthy women. Further, the set of changes in emotion was not associated with any of the changes in cytokines, though decreases in positive emotion were associated with increased $\Delta \mathrm{IL}-1 \beta$. Given that cumulative trauma was not related to changes in emotion, models examining changes in emotion as a mediator of associations between cumulative 
trauma and cytokine reactivity could not be tested. Finally, both negative and positive emotion varied over the course of the session, with negative emotion rising and then eventually falling below baseline levels but positive emotion remaining lower than baseline levels.

This study sought to extend prior research on cumulative trauma and both circulating cytokines and chronic health conditions by examining salivary cytokine responses to acute stress and including measures of IL-10, a key anti-inflammatory cytokine. In the present study, hypothesized relationships were not observed, as cumulative trauma was not statistically significantly associated with $\Delta \mathrm{IL}-10$ or $\Delta \mathrm{IL1} \beta / \mathrm{IL} 10$. This was the first study, to our knowledge, that examined associations between cumulative trauma and reactivity of salivary IL-10 and IL1 $\beta /$ IL10. Though some studies have found serum IL-10 to differ between trauma exposed and non-trauma exposed persons (Cohen et al., 2011), a recent meta-analysis found the relationship between trauma exposure and circulating IL-10 to be small in magnitude and not statistically significant (Tursich et al., 2014). This fits with the results of the present study in which there was a small relationship between greater cumulative trauma and lower IL10 increases in response to stress. In particular, this relationship was not statistically significant for cumulative overall trauma, but marginally significant for cumulative direct trauma. Thus, it appears that associations between IL-10 and trauma are small and more sensitive to direct exposure to potentially traumatic events. Future research examining IL10 and trauma exposure should consider both the distinction between direct and indirect trauma, as well as cumulative trauma. 
In terms of the IL1 $\beta / \mathrm{IL} 10$, the present study did not observe a main effect for stress in increasing the ratio, rather, there was considerable variability. This variability may reflect unmeasured differences within the samples. The IL1 $1 /$ IL10 ratio was recently found to increase in response to stress in healthy participants and the magnitude was larger in women compared to men (Szabo et al., 2016). Danielson and colleagues found pro- and anti-inflammatory cytokines to be highly positively correlated in women not in an abusive relationship, but unrelated in women in an abusive relationship, perhaps indicating less balance between pro- and anti-inflammatory cytokines in women who had experienced recent abuse (Danielson et al., 2011). The present study observed a moderate positive correlation between $\Delta \mathrm{IL} 1 \beta$ and $\Delta \mathrm{IL} 10$ in a sample that had experienced high levels of trauma, thus adding to this small body of inquiry. The examination of the relationship between pro- and anti-inflammatory cytokines is an emerging area in salivary cytokine research, though the predictive validity of the ratio for health is not yet well-understood. Future research should examine factors that predict its stress reactivity or the magnitude of the relationship between pro- and anti-inflammatory cytokines.

The present study also failed to observe hypothesized relationships between cumulative trauma and stress-reactivity of IL-1 $\beta$. This study examined cytokines in response to acute psychosocial stress among young women, which makes it difficult to compare this to other research that found greater cumulative trauma to correlate with increased salivary IL- $1 \beta$ before and after a fear and frustration paradigm in children (Tyrka et al., 2015). Other studies, however, have observed associations between trauma exposure and other pro-inflammatory cytokines in adults. Thus, it is important to consider factors that might account for differences. 
While prior research has identified associations with cytokine responses and measures of childhood trauma or recent trauma among adults, the present study used a lifetime approach among young adults. One recent study found cumulative childhood trauma to be associated with circulating serum IL-1 $\beta$ among midlife adults (Hartwell et al., 2013). Given that this was also in a mentally and physically healthy sample, the authors suggest this may be an early indicator of the later development of poor health. Thus, it is possible that the present study, which examined young adults with more recent trauma, may fail to reflect changes in cytokines that are slower to emerge. Studies that examine childhood trauma in adults may capture physiological changes that have developed slowly over time, which could explain differences in results. Additionally, comparison is made difficult due to divergent approaches in measuring trauma (i.e. cumulative childhood trauma versus cumulative trauma). Although childhood trauma has been clearly linked to poor health, measuring cumulative trauma across the lifespan may contribute further information about the additive effect of trauma exposures for health. Thus, it may be premature to stop empirical examination of the associations between cumulative trauma and cytokine reactivity. Future research should consider the impact the impact of cumulative trauma as well as childhood trauma when examining cytokine responses to stress.

Another consideration is that this study used strict inclusion criteria, making it distinguishable from prior studies that examined childhood trauma among samples of adults that included significant mental health symptoms and non-psychotropic medication use (Carpenter et al., 2010; Pace et al., 2006). Thus, associations observed in prior research may reflect the operation of unadjusted mental health symptoms indicative of 
poor health, or they could be confounded by medication use. Notably, the prevalence of trauma exposure was also higher for the present study compared to other studies using similar recruitment methodologies (Elhai et al., 2012; Gibson et al., 2014). The inclusion of a healthy sample, despite relatively higher levels of trauma exposure, may also reflect potential differences in vulnerability and protective factors in this sample. In particular, participants in this study may be highly resilient with resources to buffer against negative effects of stress, and the lack of a relationship with a pro-inflammatory response may reflect this quality.

The present study expanded on prior research by examining the unique contributions of changes in negative and positive emotion in relation to cytokines following acute stress. Contrary to hypotheses, the set of changes in emotion was not associated with cytokine reactivity. Prior research, however, has examined different cytokines, different time frames and varying domains of emotion, which may help explain the divergence in findings. We did not replicate a recent study that found increases in negative emotion to be associated with $\Delta \mathrm{IL}-1 \beta$ (Newton et al., in press). When comparing the two studies, this study recruited only women and screened out for probable health concerns. Additionally, post-stressor saliva samples in the present study were taken approximately 10 minutes earlier than samples by Newton and colleagues, due to research suggesting IL-1 $\beta$ reactivity can be captured in this time frame (Aschbacher et al., 2012; Tyrka et al., 2015). Thus, it is possible that the present study did not capture peak cytokine levels (i.e., saliva may have been collected too early or too late) which could lead to relationships not being observed. In contrast to negative emotion, the present study replicated findings between declines in positive emotion and 
increases in IL-1 $\beta$ (Aschbacher et al., 2012) and extends them to salivary IL-1 $\beta$. This finding underscores the importance of the erosion of positive emotion in the face of stress for IL-1 $\beta$. Importantly, IL-1 $\beta$ reactivity showed predictive validity for increased depression symptoms at one-year follow-up in the study by Aschbacher and colleagues. Levels of positive emotion in this study were lower at both baseline and post-stress compared to prior samples. It is possible that the observed lower levels of positive emotion restricted the ability to measure declines in positive emotion for IL-10 or the IL1//IL10 ratio. The present study hypothesized that as an extension of the broaden-andbuild theory of positive emotion (Fredrickson, 2001), positive emotion may also be a key part of resilience to stress and trauma through a lower inflammatory response in reaction to acutely stressful situations. Though only partially supported in the present study, this represents an important area for further exploration.

An important consideration while integrating these results into those of prior research is one of emotion measurement. The 20-item PANAS scales represent negatively and positively valenced emotions, as research has found valence to be the primary factor solution (Watson et al., 1988). However, it may be that these broad domains do not capture specificity in links between emotions and biological variables, which could contribute to the lack of significant findings. Indeed, inspection of prior research through this lens supports this explanation. Moons and Shields (2015) tested an avoidance/approach model for anxiety and anger, respectively, in relation to IL-1 $\beta$ measured in oral mucosa transudate and found anxiety, but not anger, was associated with increases following an emotion induction task. It is possible there may be some specificity in emotion that results in inflammatory changes which was not captured by 
aggregating negative emotions. However, this remains an empirical question for future research, as it does not match another study that found both anger and anxiety to be related to serum IL-6 (Carroll et al., 2011). In addition to specific domains of emotion, the PANAS only has scales for valence of emotion and does not distinguish different levels of arousal. Arousal, or intensity, may be an important direction for physiological and health science research (Aschbacher \& Kemeny, 2011). This is captured in the integrated specificity model, which posits that certain emotions predict certain physiological responses and that only looking at valence may obscure the specificity in these relationships (Denson, Spanovic, \& Miller, 2009). Thus, though this study was the first to examine whether stress-related negative emotion reactivity and positive emotion erosion independently contribute to cytokine reactivity, the novelty of these research questions limit the ability for definite conclusions to be drawn. Future research should continue to examine the roles of stress-related changes in emotion for cytokine reactivity, as domain of emotion, cytokine measured, fluid and measurement of both cytokines and emotion (post-stress or reactivity) are all potentially important methodological considerations.

This study also examined trait affect in relation to cytokine reactivity to determine whether associations between cytokines and state emotion reflected trait affect. There was no relationship observed between trait negative or positive emotion and change in IL-1 $\beta$, IL-10, and IL1 $\beta / I L 10$. Further, given the observed relationship between state positive emotion and IL-1 $\beta$, we wanted to confirm this was not a reflection of associations between positive trait emotion and state emotion. Trait affect being unrelated to changes in cytokines, coupled with small to negligible relationships with negative and 
positive emotion reactivity, respectively, indicate that associations between state emotion and cytokine responses do not reflect more general affective states and add to the small literature on trait affect and cytokines.

\section{Ancillary Analyses}

Ancillary analyses examined the role of post-task rumination, or thinking about the stressor during the 35-minute post-stressor period, on variables of interest. In contrast with prior research connecting trauma exposure with increased likelihood to ruminate in general (Conway, Mendelson, Giannopoulos, Csank, \& Holm, 2004), this study found greater cumulative trauma to be associated with a decreased likelihood to ruminate about the task. Tentatively, this may implicate the ability to discontinue thinking about the stressor after its cessation as a process that has helped those with greater trauma exposure to buffer the negative effects of stress. Further, likelihood of ruminating on the stressor was associated with decreases in positive emotion but not increases in negative emotion, separately. When added as a set, the model was no longer significant, but declines in positive emotion was a marginally significant as a unique contributor to the likelihood to ruminate. Prior research has found negative emotion to be associated with increased rumination (Glynn, Christenfeld, \& Gerin, 2002), which was not supported by the present study. However, this study highlights the role of declines in positive emotion in rumination. Further, this study did not find post-stressor rumination to be associated with any of the changes in cytokines. Given the open-ended nature of the question, we could not determine the content of thoughts about the stressor (i.e. rumination, reappraisal, relief) and cannot determine duration of time spent thinking about it. Further, the purpose of the non-task related cognition (e.g. self-distraction, mind wandering) cannot be 
elucidated. Other research has measured momentary rumination (Newton et al., in press) or manipulated rumination (Zoccola, Figueroa, Rabideau, Woody, \& Benencia, 2014), which may be helpful approaches to better understand how emotion and its regulation are related to cytokine responses following acute stress. It is possible that the relationship between trauma, emotion and cytokines reflects a more complex process that integrates emotional reactivity and insufficient regulation of that emotion.

A follow up analysis examining the relationship between contraceptive use and menstrual cycle phase in relation to each of the cytokines found this to be potentially relevant for IL-1 $\beta$ and IL-10, though it did not reach statistical significance. Prior research of IL-1 $1 \beta$ and IL-10 found that salivary cytokine levels were similar when measured during the luteal and follicular phases (Al-Harthi et al., 2000), and the present study suggested marginally higher reactivity for those in the luteal phase compared to those taking hormonal contraceptives. This post hoc analysis was likely underpowered, but suggests examination of both phase of menstrual cycle and contraceptive use may be important considerations when examining salivary cytokine reactivity.

Finally, this study examined changes in emotion across the laboratory session, including in reaction to the stressor as well as to completing measures on trauma exposure and positive events. Negative emotion increased in response to the stressor, but dissipated by the end of the post-stressor period. Negative emotion did not change in response to the trauma measure or the uplift scale. Conversely, positive emotion declined in response to the stressor and continued to decline during the post-stressor period. Surprisingly, positive emotion increased following completion of the trauma measure and tended to increase further following the positive event scale, though this was not 
statistically significant. This may reflect an increase in arousal after completing the trauma measure, as the PANAS captures high arousal positive emotion (e.g. HarmonJones, Harmon-Jones, Abramson, \& Peterson, 2009). However, positive emotion was still lower at the end of the session compared to baseline. In prior research using the same stress paradigm, strong negative emotional responses occur soon after stress and quickly return to baseline levels (Newton et al., in press). Together, this highlights that negative and positive emotion are not regulated at the same pace and suggests that, after acute stress, negative emotion regulates more quickly than positive emotion.

A final follow-up focused on cumulative trauma with a measure of direct trauma exposure. The pattern of findings was comparable to those for cumulative trauma exposure overall (i.e., both direct and indirect), though the relationship between cumulative direct trauma and $\Delta \mathrm{IL}-10$ was strengthened and the relationship with cumulative trauma and decreased rumination was no longer observed. Thus, differences between this study and prior literature do not reflect our inclusion of both direct and indirect exposure to trauma. This lends credence to alternate explanations for the relationships observed in this study, including a resilient sample and measuring lifespan trauma in young adults.

\section{Implications and Future Directions}

This study tested the idea that cumulative trauma is associated with emotional responses to acutely stressful situations, and this emotional response in turn is associated with physiological responses to the stressor, as measured by salivary cytokines. Overall, this model was not supported by the results of this study. Cumulative trauma was not associated with cytokine responses, nor were changes in emotion when considered 
together. However, declines in positive emotion were correlated with increases in IL-1 $\beta$. This study hypothesized that change in emotion may underlie the relationship between cumulative trauma and changes in cytokine reactivity, a hypothesis that could not be tested because a relationship between cumulative trauma and changes in emotion was not found.

The present study used a lifespan approach to measure exposure to potentially traumatic events among young adults, and measured both direct and indirect trauma exposure. Some research has found that the developmental period of trauma occurrence is a predictor of PTSD (Ogle, Rubin, \& Siegler, 2013) and much of the research on trauma and cytokines has focused on childhood trauma. Thus, operationalization of cumulative trauma varies across studies, which may contribute to discrepant findings and the significance of when trauma occurs and specific types (e.g. childhood trauma) versus overall cumulative exposure are still empirical questions being answered.

Further, there may be some specificity in relationships between cumulative trauma, emotion and cytokines. Though IL-1 $\beta$ has been connected to cumulative trauma in children, the research on cumulative trauma and acute stress in adults examined IL-6. Further, prior research on negative emotion focused on IL-6, findings that were extended to salivary IL-1 $\beta$ in one study (Newton et al., in press) but not found in this study. Though both IL-1 $\beta$ and IL-6 have pro-inflammatory functions, these cytokines are unique - IL-1 $\beta$ is an inducer of IL-6 (Dinarello, 2000) and IL-6 can have both pro- and antiinflammatory functions (Scheller, Chalaris, Schmidt-Arras, \& Rose-John, 2011). This may suggest that trauma and emotion hold unique relationships with different aspects of 
the pro-inflammatory response. Prior research had not examined IL-10, or the IL1 $\beta /$ IL10 ratio, thus the nascence of these questions limits the ability to draw conclusions.

An important consideration when contextualizing the findings of this study is recruitment and participant characteristics. This study expanded on prior observational and correlational studies examining cumulative trauma, emotion and cytokine reactivity to acute stress by screening participants for potential confounding variables. Though this study relied on self-report of symptoms and diagnosed disorders to exclude ineligible participants, mental health symptoms for participants who completed the study were low compared to other published studies (e.g. Khubchandani, Brey, Kotecki, Kleinfelder, \& Anderson, 2016), suggesting that this was a healthy sample. This strict inclusion criteria may be further demonstrated by lower median cytokine levels in the present study compared to other published samples of salivary cytokines (Szabo et al., 2016). The levels observed in this sample are within ranges reported in other studies, though concentrated at the lower ends of the distribution, and may reflect a subsample of the population.

One possible consequence of this screening process is that the sample included women with resources to buffer the effects of negative life stress and maintain good health despite their trauma histories. In support of this, trait negative affect was lower than other published samples. Thus, relationships observed in the present study may reflect unique processes in a resilient sample. Prior research has observed that positive correlations between salivary IL-6 levels and negative emotion differentiated traumaexposed persons who showed persistent distress from those who were either resistant to distress, or recovered from it (Newton, Fernandez-Botran, Miller, \& Burns, 2014). 
Specifically, those who were resistant to PTSD (i.e., not displaying significant symptoms at two time points), did not demonstrate a correlation between negative emotion and salivary IL-6, which fits with the findings of the present study. Together, this may suggest that the hypothesized relationships are not observed in resilient people, who have maintained health despite trauma exposure. This sample, characterized by low mental health symptoms, low trait negative affect and low cytokine responses despite relatively higher levels of trauma exposure, could be considered exceptionally healthy. Further, a relationship between greater trauma exposure and less rumination, as well as a lack of relationship between negative emotion and salivary cytokines, offers potential support for the processes that illustrate resilience in the face of stress. Should this be supported in future research, the next line of inquiry would be to identify mechanisms that explain this phenomena.

The present study extends understanding of salivary cytokine reactivity. Inflammation is a compartmentalized process and salivary cytokines represent local production of cytokines in a mucosal cavity. In addition to cytokines that may filter from plasma, cytokines are also produced by lymphocytes in the oral mucosa and salivary glands (Khan et al, 2003). Saliva is comprised of oral fluids that filter from plasma through the oral mucosa via crevicular fluid as well as produced by individual salivary glands (Bosch, 2014; Kaufman \& Lamster, 2002). Given that saliva is a watery fluid and has many other proteins present, it may be possible that differential relationships will be observed or that effect sizes may be smaller compared to cytokines measured in other fluids. Salivary inflammatory markers demonstrated diagnostic validity for some disorders, including HIV and Sjorgren's disease (Lima, Diniz, Moimaz, Sumida, \& 
Okamoto, 2010). Thus, better understanding of salivary cytokines may provide unique perspectives on how psychological factors relate to health.

One consideration for future research is timing of samples to capture peak reactivity to stress. This study took one saliva sample 45 minutes after the onset of the stressor. Though based on timing for IL-1 $\beta$ and IL-10 in prior research and the little work published on salivary cytokine responses to stress (Izawa et al., 2013; Newton et al., in press; Szabo et al., 2016), it is possible that collecting saliva at the time in this study missed the peak in cytokine responses. Collecting samples prior to peak levels or after they occur could lead to conclusions that predictors are unrelated. Given examination of salivary cytokines is an emerging area of research, future research should study the time points of the salivary stress response for both pro- and anti- inflammatory cytokines and consider change over time. It may be possible that two samples would be needed, one for peak pro-inflammatory cytokine levels and one for peak anti-inflammatory cytokine levels.

Additionally, future research is needed on the predictive validity of salivary cytokines for peripheral stress systems. Correlations between cytokines measured in blood and saliva have ranged from small to moderate (Dan et al., 2011; FernandezBotran, Miller, Burns, \& Newton, 2011) to large (Wang, Mandel, Levingston, \& Young, 2016) in magnitude, suggesting that salivary cytokines likely reflect local rather than systemic inflammation. However, research suggests that some of the same neural mechanisms that mediate circulating cytokine responses also correlate with salivary IL$1 \beta$ (O'Connor et al., 2009). Importantly, such research has not yet been extended to antiinflammatory cytokines or the ratio of pro-and anti-inflammatory cytokines, which would 
further our understanding of the predictive validity of salivary cytokines. Therefore, salivary cytokines may be helpful in understanding psychological phenomena, but the predictive validity of salivary cytokine reactivity has yet to be elucidated.

\section{Limitations}

This study extends our understanding of relationships between cumulative trauma, stress-related changes in emotion and salivary cytokine reactivity to acute stress. The contributions of this study should be interpreted in the context of several limitations. First, recruitment for the study was strict, requiring both mentally and physically healthy women, to strengthen internal validity. Thus, though a strength in terms of internal validity, results may not be generalizable to men, samples with different levels of trauma exposure, or increased levels of cytokines. Second, this study used a cumulative approach to measuring trauma exposure and used a checklist to assess for potentially traumatic events. Though this study was not focused on diagnostic status, there was not a procedure for verifying that events endorsed met the DSM criteria of trauma exposure that would be required for a PTSD diagnosis. While this measure was selected for the broad inclusion of a range of potentially traumatic events consistent with the newest diagnostic criteria as well as the distribution in amount of exposure observed in college students (Gibson et al., 2014), this is a potential limitation of this study, as well of this measure as a self-report instrument.

\section{Conclusions}

This study explored a potential pathway through which trauma exposure may be associated with a part of the immune system, and, ultimately, poor health. Specifically, this study examined how cumulative trauma exposure and state emotion were associated 
with salivary cytokine stress reactivity in a sample of healthy women. Cumulative trauma was not related to any of the cytokines and a mediational pathway could not be tested. However, this study underscores the importance of positive emotion in changes in IL-1 $\beta$. Future directions include examining these relationships in a sample with less cumulative trauma exposure and less strict inclusion criteria, as well as with other domains of emotion. This study contributes to the growing literature that examines how trauma exposure may relate to the development of poor health. The pathways between psychosocial factors and health are still being understood and findings of this study add to the burgeoning body of research in trauma, emotion, and cytokines. With better understanding of how these factors influence stress and inflammation, intervention to change the pathological trajectory of poor health following exposure to stress and trauma may someday be possible. 


\section{REFERENCES}

Al-Harthi, L., Wright, D. J., Anderson, D., Cohen, M., Matity Ahu, D., Cohn, J., CuUnvin, S., Burns, D., Reichelderfer, P., Lewis, S., Beckner, S., Kovacs, A., \& Landay, A. (2000). The impact of the ovulatory cycle on cytokine production: evaluation of systemic, cervicovaginal, and salivary compartments. Journal of Interferon \& Cytokine Research, 20(8), 719-724.

doi:10.1089/10799900050116426

American Psychiatric Association (2013). Diagnostic and Statistical Manual of Mental Disorders (5th ed.). Washington, DC: American Psychiatric Association.

Aschbacher, K., Epel, E., Wolkowitz, O. M., Prather, A. A., Puterman, E., \& Dhabhar, F. S. (2012). Maintenance of a positive outlook during acute stress protects against pro-inflammatory reactivity and future depressive symptoms. Brain, Behavior, and Immunity, 26(2), 346-352. doi:10.1016/j.bbi.2011.10.010

Aschbacher, K., \& Kemeny, M. E. (2011). New directions in linking the dynamics of affective and stress-arousal systems. Brain, Behavior, and Immunity, 25(2), 230231. doi:10.1016/j.bbi.2010.10.025

Behar, E., Alcaine, O., Zuellig, A. R., \& Borkovec, T. D. (2003). Screening for generalized anxiety disorder using the Penn State Worry Questionnaire: a receiver operating characteristic analysis. Journal of Behavior Therapy and Experimental Psychiatry, 34(1), 25-43. 
Berg, A. H., \& Scherer, P. E. (2005). Adipose tissue, inflammation, and cardiovascular disease. Circulation Research, 96(9), 939-949.

doi:10.1161/01.RES.0000163635.62927.34

Bosch, J. A. (2014). The use of saliva markers in psychobiology: mechanisms and methods. . Saliva: Secretion and Functions, 24, 99-108.

Brummett, B. H., Boyle, S. H., Ortel, T. L., Becker, R. C., Siegler, I. C., \& Williams, R. B. (2010). Associations of depressive symptoms, trait hostility, and gender with C-reactive protein and interleukin-6 response after emotion recall. Psychosomatic Medicine, 72(4), 333-339. doi:10.1097/PSY.0b013e3181d2f104

Buhlin, K., Gustafsson, A., Andersson, K., Hakansson, J., \& Klinge, B. (2002). Validity and limitations of self-reported periodontal health. Community Dentistry and Oral Epidemiology, 30(6), 431-437.

Carpenter, L. L., Gawuga, C. E., Tyrka, A. R., Lee, J. K., \& Anderson, G. M. P., L. H. . (2010). Association between plasma IL-6 response to acute stress and early-life adversity in healthy adults. Neuropsychopharmacology, 35(13), 2617-2623.

Carroll, J. E., Low, C. A., Prather, A. A., Cohen, S., Fury, J. M., Ross, D. C., \& Marsland, A. L. (2011). Negative affective responses to a speech task predict changes in interleukin (IL)-6. Brain, Behavior, and Immunity, 25(2), 232-238. doi:10.1016/j.bbi.2010.09.024

Centers for Disease Control and Prevention (2013). Leading Causes of Death in Males United States, 2013 (current listing). Retrieved from http://www.cdc.gov/men/lcod/2013/index.htm 
Centers for Disease Control and Prevention (2013). Leading Causes of Death in Females United States, 2013 (current listing). Retrieved from http://www.cdc.gov/women/lcod/2013/index.htm

Cohen, M., Meir, T., Klein, E., Volpin, G., Assaf, M., \& Pollack, S. (2011). Cytokine levels as potential biomarkers for predicting the development of posttraumatic stress symptoms in casualties of accidents. International Journal of Psychiatry Medicine, 42(2), 117-131.

Conway, M., Mendelson, M., Giannopoulos, C., Csank, P. A., \& Holm, S. L. (2004). Childhood and adult sexual abuse, rumination on sadness, and dysphoria. Child Abuse \& Neglect, 28(4), 393-410. doi:10.1016/j.chiabu.2003.05.004

Dan, H., Liu, W., Wang, J., Wang, Z., Wu, R., Chen, Q., Zeng, X. \& Zhou, Y. (2011). Elevated IL-10 concentrations in serum and saliva from patients with oral lichen planus. Child Abuse and Neglect, 42(2), 157-163.

Danielson, A. M., Matheson, K., \& Anisman, H. (2011). Cytokine levels at a single time point following a reminder stimulus among women in abusive dating relationships: Relationship to emotional states. Psychoneuroendocrinology, 36(1), 40-50.

Denson, T. F., Spanovic, M., \& Miller, N. (2009). Cognitive appraisals and emotions predict cortisol and immune responses: a meta-analysis of acute laboratory social stressors and emotion inductions. Psychological Bulletin, 135(6), 823-853. doi:10.1037/a0016909

Denton, M., Prus, S., \& Walters, V. (2004). Gender differences in health: a Canadian study of the psychosocial, structural and behavioural determinants of health. 
Social Science and Medicine, 58(12), 2585-2600.

doi:10.1016/j.socscimed.2003.09.008

Dhabhar, F. S., Burke, H. M., Epel, E. S., Mellon, S. H., Rosser, R., Reus, V. I., \& Wolkowitz, O. M. (2009). Low serum IL-10 concentrations and loss of regulatory association between IL-6 and IL-10 in adults with major depression. Journal of Psychiatric Research, 43(11), 962-969.

Dinarello, C. A. (1988). Biology of interleukin 1. FASEB Journal, 2(2), 108-115.

Dinarello, C. A. (2000). Proinflammatory cytokines. Chest, 118(2), 503-508.

Dowlati, Y., Herrmann, N., Swardfager, W., Liu, H., Sham, L., Reim, E. K., \& Lanctot, K. L. (2010). A meta-analysis of cytokines in major depression. Biological Psychiatry, 67(5), 446-457. doi:10.1016/j.biopsych.2009.09.033

Elhai, J. D., Miller, M. E., Ford, J. D., Biehn, T. L., Palmieri, P. A., \& Frueh, B. C. (2012). Posttraumatic stress disorder in DSM-5: Estimates of prevalence and symptom structure in a nonclinical sample of college students. Journal of Anxiety Disorders, 26(1), 58-64. doi:10.1016/j.janxdis.2011.08.013

Fernandez-Botran, R., Miller, J. J., Burns, V. E., \& Newton, T. L. (2011). Correlations among inflammatory markers in plasma, saliva and oral mucosal transudate in post-menopausal women with past intimate partner violence. Brain, Behavior, and Immunity, 25(2), 314-321. doi:10.1016/j.bbi.2010.09.023

Folkman, S., \& Moskowitz, J. T. (2000). Positive affect and the other side of coping. American Psychologist, 55(6), 647-654. 
Fredrickson, B. L. (2001). The role of positive emotions in positive psychology. The broaden-and-build theory of positive emotions. American Psychologist, 56(3), 218-226.

Gerin, W., Davidson, K. W., Christenfeld, N. J., Goyal, T., \& Schwartz, J. E. (2006). The role of angry rumination and distraction in blood pressure recovery from emotional arousal. Psychosomatic Medicine, 68(1), 64-72. doi:10.1097/01.psy.0000195747.12404.aa

Gibson, L. E., Anglin, D. M., Klugman, J. T., Reeves, L. E., Fineberg, A. M., Maxwell, S. D., Kerns, C.M., \& Ellman, L. M. (2014). Stress sensitivity mediates the relationship between traumatic life events and attenuated positive psychotic symptoms differentially by gender in a college population sample. Journal of Psychiatric Research, 53, 111-118.

Glynn, L. M., Christenfeld, N., \& Gerin, W. (2002). The role of rumination in recovery from reactivity: cardiovascular consequences of emotional states. Psychosomatic Medicine, 64(5), 714-726.

Gray, M. J., Litz, B. T., Hsu, J. L., \& Lombardo, T. W. (2004). Psychometric properties of the life events checklist. Assessment, 11(4), 330-341. doi:10.1177/1073191104269954

Groer, M. W., Thomas, S. P., Evans, G. W., Helton, S., \& Weldon, A. (2006). Inflammatory effects and immune system correlates of rape. Violence and Victims, 21(6), 796-808. 
Gross, J. J., \& Thompson, R. A. (2007). Emotion Regulation: Conceptual Foundations. In J. J. Gross (Ed.), Handbook of Emotion Regulation (pp. 3-24). New York: Guilford Press.

Harmon-Jones, E., Harmon-Jones, C., Abramson, L., \& Peterson, C. K. (2009). PANAS positive activation is associated with anger. Emotion, 9(2), 183-196.

Hartwell, K. J., Moran-Santa Maria, M. M., Twal, W. O., Shaftman, S., DeSantis, S. M., McRae-Clark, A. L., \& Brady, K. T. (2013). Association of elevated cytokines with childhood adversity in a sample of healthy adults. Journal of Psychiatric Research, 47(5), 604-610.

Heagy, W., Nieman, K., Hansen, C., Cohen, M., Danielson, D., \& West, M. A. (2003). Lower levels of whole blood LPS-stimulated cytokine release are associated with poorer clinical outcomes in surgical ICU patients. Surgical Infections, 4(2), 171180. doi:10.1089/109629603766956960

Izawa, S., Sugaya, N., Kimura, K., Ogawa, N., Yamada, K. C., Shirotsuki, K., Mikami, I., Hirata, K., Nagano, Y. \& Nomura, S. (2013). An increase in salivary interleukin-6 level following acute psychosocial stress and its biological correlates in healthy young adults. Biological Psychology, 94(2), 249-254.

doi:10.1016/j.biopsycho.2013.06.006

Kaufman, E., \& Lamster, I. B. (2002). The diagnostic applications of saliva--a review. Critical Reviews in Oral Biology \& Medicine, 13(2), 197-212.

Kelly, M. M., Tyrka, A. R., Anderson, G. M., Price, L. H., \& Carpenter, L. L. (2008). Sex differences in emotional and physiological responses to the Trier Social 
Stress Test. Journal of Behavior Therapy and Experimental Psychiatry, 39(1), 8798. doi:10.1016/j.jbtep.2007.02.003

Kendall-Tackett, K. (2009). Psychological trauma and physical health: a psychoneuroimmunology approach to etiology of negative health effects and possible interventions. Psychological Trauma: Theory, research, practice, and policy, 1(1), 35-48.

Khan, A., Farah, C. S., Savage, N. W., Walsh, L. J., Harbrow, D. J., \& Sugerman, P. B. (2003). Th1 cytokines in oral lichen planus. Journal of oral pathology \& medicine, 32(2), 77-83.

Khubchandani, J., Brey, R., Kotecki, J., Kleinfelder, J., \& Anderson, J. (2016). The psychometric properties of PHQ-4 depression and anxiety screening scale among college students. Archives of psychiatric nursing, 30(4), 457-462.=

Kirschbaum, C., \& Hellhammer, D. H. (1994). Salivary cortisol in psychoneuroendocrine research: Recent developments and applications. Psychoneuroendocrinology, 19(4), 313-333.

Kirschbaum, C., Pirke, K. M., \& Hellhammer, D. H. (1993). The 'Trier Social Stress Test'--a tool for investigating psychobiological stress responses in a laboratory setting. Neuropsychobiology, 28(1-2), 76-81. doi:119004

Kroenke, K., Spitzer, R. L., Williams, J. B., \& Lowe, B. (2009). An ultra-brief screening scale for anxiety and depression: the PHQ-4. Psychosomatics, 50(6), 613-621. doi:10.1176/appi.psy.50.6.613 
Kroenke, K., Spitzer, R. L., Williams, J. B., Monahan, P. O., \& Lowe, B. (2007). Anxiety disorders in primary care: prevalence, impairment, comorbidity, and detection. Annals of Internal Medicine, 146(5), 317-325.

Kronfol, Z., \& Remick, D. G. (2000). Cytokines and the brain: implications for clinical psychiatry. American Journal of Psychiatry, 157(5), 683-694.

LaMonte, M. J., Hovey, K. M., Millen, A. E., Genco, R. J., \& Wactawski-Wende, J. (2014). Accuracy of self-reported periodontal disease in the Women's Health Initiative Observational Study. Journal of Periodontology, 85(8), 1006-1018. doi:10.1902/jop.2013.130488

Lima, D. P., Diniz, D. G., Moimaz, S. A., Sumida, D. H., \& Okamoto, A. C. (2010). Saliva: reflection of the body. International Journal of Infectious Diseases, 14(3), e184-188. doi:10.1016/j.ijid.2009.04.022

Lowe, B., Kroenke, K., \& Grafe, K. (2005). Detecting and monitoring depression with a two-item questionnaire (PHQ-2). Journal of Psychosomatic Research, 58(2), 163171. doi:10.1016/j.jpsychores.2004.09.006

Luc, G., Bard, J. M., Juhan-Vague, I., Ferrieres, J., Evans, A., Amouyel, P., \& Ducimetiere, P. (2003). C-reactive protein, interleukin-6, and fibrinogen as predictors of coronary heart disease: The PRIME study. Arteriosclerosis, Thrombosis, and Vascular Biology, A23(7), 1255-1261.

Lynch, E. A., Dinarello, C. A., \& Cannon, J. G. (1994). Gender differences in IL-1 alpha, IL-1 beta, and IL-1 receptor antagonist secretion from mononuclear cells and urinary excretion. Journal of Immunology, 153(1), 300-306. 
Marsland, A. L., Prather, A. A., Petersen, K. L., Cohen, S., \& Manuck, S. B. (2008). Antagonistic characteristics are positively associated with inflammatory markers independently of trait negative emotionality. Brain, Behavior, and Immunity, 22(5), 753-761. doi:10.1016/j.bbi.2007.11.008

Mayberry, D. J. (2013). Positive Event (uplift) Scale for University Students. Measurement Instrument Database for the Social Science, Retrieved from www.midss.ie.

McLaughlin, K. A., Kubzansky, L. D., Dunn, E. C., Waldinger, R., Vaillant, G., \& Koenen, K. C. (2010). Childhood social environment, emotional reactivity to stress, and mood and anxiety disorders across the life course. Depression and Anxiety, 27(12), 1087-1094. doi:10.1002/da.20762

McLaughlin, K. A., Peverill, M., Gold, A. L., Alves, S., \& Sheridan, M. A. (2015). Child Maltreatment and Neural Systems Underlying Emotion Regulation. Journal of the American Academy of Child and Adolescent Psychiatry, 54(9), 753-762. doi:10.1016/j.jaac.2015.06.010

Mills, K. L., McFarlane, A. C., Slade, T., Creamer, M., Silove, D., Teesson, M., \& Bryant, R. (2011). Assessing the prevalence of trauma exposure in epidemiological surveys. Australian and New Zealand Journal of Psychiatry, 45(5), 407-415. doi:10.3109/00048674.2010.543654

Moons, W. G., Eisenberger, N. I., \& Taylor, S. E. (2010). Anger and fear responses to stress have different biological profiles. Brain, Behavior, and Immunity, 24(2), 215-219. 
Moons, W. G., \& Shields, G. S. (2015). Anxiety, not anger, induces inflammatory activity: An avoidance/approach model of immune system activation. Emotion, 15(4), 463-476. doi:10.1037/emo0000055

Myin-Germeys, I., Krabbendam, L., Delespaul, P. A., \& van Os, J. (2004). Sex differences in emotional reactivity to daily life stress in psychosis. Journal of Clinical Psychiatry, 65(6), 805-809.

National Alliance on Mental Illness. (2016). Mental Health By the Numbers. Retrieved from https://www.nami.org/Learn-More/Mental-Health-By-the-Numbers

Newton, T. L., Fernandez-Botran, R., Lyle, K. B., Szabo, Y. Z., Miller, J. J., \& Warnecke, A. (in press). Salivary cytokine response in the aftermath of stress: An emotion regulation perspective. Emotion.

Newton, T. L., Fernandez-Botran, R., Miller, J. J., \& Burns, V. E. (2014). Interleukin-6 and soluble interleukin-6 receptor levels in posttraumatic stress disorder: associations with lifetime diagnostic status and psychological context. Biological Psychology, 99, 150-159. doi:10.1016/j.biopsycho.2014.03.009

O'Connor, M. F., Irwin, M. R., \& Wellisch, D. K. (2009). When grief heats up: proinflammatory cytokines predict regional brain activation. Neuroimage, 47(3), 891-896. doi:10.1016/j.neuroimage.2009.05.049

Ogle, C. M., Rubin, D. C., \& Siegler, I. C. (2013). The impact of the developmental timing of trauma exposure on PTSD symptoms and psychosocial functioning among older adults. Developmental Psychology, 49(11), 2191-2200.

Opal, S. M., \& DePalo, V. A. (2000). Anti-inflammatory cytokines. Chest, 117(4), $1162-$ 1172. 
Pabst, S., Brand, M., \& Wolf, O. T. (2013). Stress effects on framed decisions: there are differences for gains and losses. Frontiers in Behavioral Neuroscience, 7(142), 110.

Pace, T. W., Mletzko, T. C., Alagbe, O., Musselman, D. L., Nemeroff, C. B., Miller, A. H., \& Heim, C. M. (2006). Increased stress-induced inflammatory responses in male patients with major depression and increased early life stress. American Journal of Psychiatry, 163(9), 1630-1633. doi:10.1176/appi.ajp.163.9.1630

Prather, A. A., Marsland, A. L., Muldoon, M. F., \& Manuck, S. B. (2007). Positive affective style covaries with stimulated IL-6 and IL-10 production in a middleaged community sample. Brain, Behavior, and Immunity, 21(8), 1033-1037. doi:10.1016/j.bbi.2007.04.009

Pressman, S. D., \& Cohen, S. (2005). Does positive affect influence health? Psychological Bulletin, 131(6), 925-971.

Prins, A., Ouimette, P., Kimerling, R., Cameron, R. P., Hugelshofer, D. S., ShawHegwer, J., Thraikill, A. Gusman, F.D., Sheikh, J. I. (2003). The primary care PTSD screen (PC-PTSD): development and operating characteristics Primary Care Psychiatry, 9(1), 9-14.

Puterman, E., Epel, E. S., O’Donovan, A., Prather, A. A., Aschbacher, K., \& Dhabhar, F. S. (2014). Anger is associated with increased IL-6 stress reactivity in women, but only among those low in social support. International Journal of Behavioral Medicine, 21(6), 936-945. 
Remarque, E. J., Bollen, E. L., Weverling-Rijnsburger, A. W., Laterveer, J. C., Blauw, G. J., \& Westendorp, R. G. (2001). Patients with Alzheimer's disease display a proinflammatory phenotype. Experimental Gerontology, 36(1), 171-176.

Roberts, A. L., Gilman, S. E., Breslau, J., Breslau, N., \& Koenen, K. C. (2011). Race/ethnic differences in exposure to traumatic events, development of posttraumatic stress disorder, and treatment-seeking for post-traumatic stress disorder in the United States. Psychological Medicine, 41(1), 71-83. doi:10.1017/S0033291710000401

Scheller, J., Chalaris, A., Schmidt-Arras, D., \& Rose-John, S. (2011). The pro- and antiinflammatory properties of the cytokine interleukin-6. Biochim Biophys Acta, 1813(5), 878-888. doi:10.1016/j.bbamcr.2011.01.034

Scott, K. M., Koenen, K. C., Aguilar-Gaxiola, S., Alonso, J., Angermeyer, M. C., Benjet, C., Bruffaerts, R., Caldas-de-Almeida, J. M. , de Girolamo, G., Florescu, S., Iwata, N., Levinson, D., Lim, C. C., Murphy, S., Ormel, J., Posada-Villa, J., \& Kessler, R. C. (2013). Associations between lifetime traumatic events and subsequent chronic physical conditions: a cross-national, cross-sectional study. PloS one, 8(11), e80573.

Slavish, D. C., Graham-Engeland, J. E., Smyth, J. M., \& Engeland, C. G. (2015). Salivary markers of inflammation in response to acute stress. Brain, Behavior, and Immunity, 44, 253-269. doi:10.1016/j.bbi.2014.08.008

Steptoe, A., Hamer, M., \& Chida, Y. (2007). The effects of acute psychological stress on circulating inflammatory factors in humans: a review and meta-analysis. Brain, Behavior, and Immunity, 21(7), 901-912. doi:10.1016/j.bbi.2007.03.011 
Szabo, Y. Z., Newton, T. L., Miller, J. J., Lyle, K. B., \& Fernandez-Botran, R. (2016). Acute stress induces increases in salivary IL-10 levels. Stress, 19(5), 499-505.

Taniguchi, T., Koido, Y., Aiboshi, J., Yamashita, T., Suzaki, S., \& Kurokawa, A. (1999). Change in the ratio of interleukin- 6 to interleukin-10 predicts a poor outcome in patients with systemic inflammatory response syndrome. Critical Care Medicine, $27(7), 1262-1264$.

Tomaka, J., Blascovich, J., Kibler, J., \& Ernst, J. M. (1997). Cognitive and physiological antecedents of threat and challenge appraisal. Journal of Personality and Social Psychology, 73(1), 63-72.

Tracy, M., Morgenstern, H., Zivin, K., Aiello, A. E., \& Galea, S. (2014). Traumatic event exposure and depression severity over time: results from a prospective cohort study in an urban area. Social Psychiatry and Psychiatric Epidemiology, 49(11), 1769-1782. doi:10.1007/s00127-014-0884-2

Tursich, M., Neufeld, R. W., Frewen, P. A., Harricharan, S., Kibler, J. L., Rhind, S. G., \& Lanius, R. A. (2014). Association of trauma exposure with proinflammatory activity: a transdiagnostic meta-analysis. Translational Psychiatry, 4, e413. doi:10.1038/tp.2014.56

Tyrka, A. R., Parade, S. H., Valentine, T. R., Eslinger, N. M., \& Seifer, R. (2015). Adversity in preschool-aged children: Effects on salivary interleukin-1beta. Developmental Psychopathology, 27(2), 567-576. doi:10.1017/S0954579415000164

Wang, Z., Mandel, H., Levingston, C. A., \& Young, M. R. (2016). An exploratory approach demonstrating immune skewing and a loss of coordination among 
cytokines in plasma and saliva of Veterans with combat-related PTSD. Human Immunology, 77(8), 652-657. doi:10.1016/j.humimm.2016.05.018

Watson, D., Clark, L. A., \& Tellegen, A. (1988). Development and validation of brief measures of positive and negative affect: the PANAS scales. Journal of Personality and Social Psychology, 54(6), 1063-1070.

Weathers, F. W., Litz, B. T., Keane, T. M., Palmieri, P. A., Marx, B. P., \& Schnurr, P. P. (2013). The PTSD Checklist for DSM-5 (PCL-5). Scale available from the National Center for PTSD at www.ptsd.va.gov.

Whembolua, G. L., Granger, D. A., Singer, S., Kivlighan, K. T., \& Marguin, J. A. (2006). Bacteria in the oral mucosa and its effects on the measurement of cortisol, dehydroepiandrosterone, and testosterone in saliva. Hormones and Behavior, 49(4), 478-483. doi:10.1016/j.yhbeh.2005.10.005

Willis, C., Morris, J. M., Danis, V., \& Gallery, E. D. (2003). Cytokine production by peripheral blood monocytes during the normal human ovulatory menstrual cycle. Human Reproducation, 18(6), 1173-1178.

Zoccola, P. M., Figueroa, W. S., Rabideau, E. M., Woody, A., \& Benencia, F. (2014). Differential effects of poststressor rumination and distraction on cortisol and Creactive protein. Health Psychology, 33(12), 1606-1609. doi:10.1037/hea0000019 


\section{APPENDIX A}

\section{Funding Sources}

Funding was provided by four sources, which funded materials for this study, assays for saliva samples and a lottery for a subsample of participants completing the study.

\section{Sponsorship}

Amount of Award: \$250, awarded to Yvette Szabo, MA

Agency: University of Louisville Women's Center

\section{Grant Funding}

Title: Research and Creative Activities Grant

PIs: Tamara Newton, PhD, Yvette Szabo, MA

Dates: July 2016- July 2017

Amount of Award: \$811, awarded to Yvette Szabo, MA

Agency: University of Louisville College of Arts \& Sciences

Psi Chi Spring Graduate Research Grant

PIs: Tamara Newton, PhD, Yvette Szabo, MA

Dates: March 2016-March 2017

Amount of Award: \$1,151.27, awarded to Yvette Szabo, MA

Agency: Psi Chi, the International Honors Society in Psychology

Graduate Student Council Research Grant

PIs: Tamara Newton, PhD, Yvette Szabo, MA

Dates: November 2015-November 2016

Amount of Award: \$300, awarded to Yvette Szabo, MA

Agency: Graduate Student Council, University of Louisville 


\section{CURRICULUM VITAE}

Yvette Z. Szabo, MA

2002 Holcombe Boulevard

Houston, TX 77030

(713) 791-1414 ext 24621

yvette.szabo@va.gov

yzszabo@gmail.com

Current Roles

2016-present

2015-present

Education

2014-present

2012-2014

2008-2012

\section{Psychology Intern}

Michael E. DeBakey VA Medical Center, Houston, Texas

Doctoral Candidate

University of Louisville, Louisville, KY

\section{PhD Clinical Psychology, APA-Accredited}

University of Louisville, Louisville, KY

Dissertation: Cumulative Trauma Exposure, Emotion Reactivity

and Salivary Cytokine Response Following Acute Stress Among

Healthy Women

Mentor: Tamara Newton, $\mathrm{PhD}$

Anticipated graduation: August 2017

MA Clinical Psychology, APA-Accredited

University of Louisville, Louisville, KY

Thesis: Health Risks in Midlife Women: The Roles of Cumulative

Trauma and Posttraumatic Stress

Mentor: Tamara Newton, PhD

BS Psychology, Neuroscience emphasis

Honors, Summa Cum Laude

San José State University, San José, CA

Minors in Business, Nutrition \& Food Science 
$\underline{\text { Awards and Honors }}$

2016

2016

2015

2015

2014

2013-2014

2013-2014

2013

2012

2009-2012

2009-2010

2009-2010
Dissertation Research Sponsorship

University of Louisville Women's Center

American Psychological Association - Basic Science Grant Honorable Mention 2015/2016

American Association for the Advancement of Science

Nominated for membership based on excellence in research

Campus Representative Excellence in Campus Leadership

American Psychological Association of Graduate Students

Minority Initiative Travel Scholarship

American Psychosomatic Society

Dr. M. Celeste Nichol Award Recipient

University of Louisville Women's Center

Graduate Student Union Research Fund Recipient

University of Louisville, College of Arts \& Sciences

National Science Foundation Graduate Fellowship

Honorable Mention 2012/2013

Psi Chi Regional Research Award Recipient

Western Psychological Association Conference

Dean's Scholar

San José State University

Gerald Wheeler Scholarship Recipient

San José State University, College of Social Sciences

Ronald G. Rabedeau Memorial Scholarship Recipient

San José State University, Department of Psychology

Grants and Fellowships

July 2016-

July 2017
Research and Creative Activities Grant

Source: University of Louisville College of Arts \& Sciences PIs: Tamara Newton, PhD, Yvette Szabo, MA

Project Title: "Associations Between Cumulative Trauma

Exposure, Emotion and Salivary Cytokine Response Following Acute Stress"

Amount of Award: \$811, awarded to Yvette Szabo, MA 
March 2016-

March 2017

November 2015

present

December 2013-

December 2014
Psi Chi Spring Graduate Research Grant

Source: Psi Chi, the International Honors Society in Psychology

PIs: Tamara Newton, PhD, Yvette Szabo, MA

Project Title: “Associations Between Cumulative Trauma

Exposure, Emotion and Salivary Cytokine Response Following

Acute Stress"

Amount of Award: \$ 1,151.27, awarded to Yvette Szabo, MA

Graduate Student Council Research Grant

Source: Graduate Student Council, University of Louisville

PIs: Tamara Newton, PhD, Yvette Szabo, MA

Project Title: Associations Between Cumulative Trauma Exposure, Emotion and Salivary Cytokine Response Following Acute Stress

Amount of Award: \$300, awarded to Yvette Szabo, MA

Psi Chi Fall Graduate Research Grant

Source: Psi Chi, the International Honors Society in Psychology

PI: Tamara Newton, PhD

Project Title: "The Detection and Stress Reactivity of Interleukin 10 (IL-10) in Oral Fluids"

Amount of Award: \$1,170, awarded to Yvette Szabo, MA

July 2012-

June 2014
University of Louisville Graduate Fellowship

School of Interdisciplinary and Graduate Studies

Nominated by department for fellowship designed to recruit doctoral students based on GRE scores, grades, scholarly

ability and letters of recommendation

\section{Publications}

Szabo, Y.Z., Warnecke, A.J., Newton, T.L., \& Valentine, J., (in press). Associations between rumination and posttraumatic symptoms: A systematic review and metaanalysis.

Newton, T.L., Fernandez-Botran, R., Lyle, K.B, Szabo, Y.Z., Miller, J.J., \& Warnecke, A.J. (in press).Co-regulation of Emotion and Salivary Inflammation in the Aftermath of Stress, Emotion

Warnecke, A.J., Szabo, Y.Z., Burns, V.E., Miller, J.J., Fernandez-Botran, \& Newton, T.L. (in press). Sheltering for Safety in Community Women with Divorce Histories, Violence and Victims

Szabo, Y.Z., Newton, T.L., Miller, J.J., Lyle, K.B. \& Fernandez-Botran, R. (2016). Acute Stress Induces Increases in IL-10 in Saliva, Stress, 19 (5), 499-505. 
Szabo, Y.Z., Chang, A. \& Chancellor-Freeland, C. (2015). Locus of Control Predicts Cortisol Reactivity and Speech Performance in Response to Acute Stress in Undergraduate Students, College Student Journal, 49(2), 225-236.

\section{Manuscripts in Progress}

Szabo, Y.Z., Fernandez-Botran, R., \& Newton, T.L. (In Preparation). The Potential Regulating Role of Positive Affect in Associations between Trauma Exposure and Health: A Place for Inflammation?

Patton, S.C., Szabo, Y.Z., \& Newton, T.L. (In Preparation). Mental and physical health trajectories after leaving an abusive partner: A systematic review

Szabo, Y.Z., Chase, T.E., Hiatt, E. and Teng, E. (In Preparation). Unique contributions of Anxiety Sensitivity and Difficulties in Emotion Regulation in Veterans with Panic Disorder

\section{National or International Conference Presentations}

Patton, S.C., Szabo, Y.Z., \& Newton, T.L. (November, 2016). Mental and physical health trajectories after leaving an abusive partner: A systematic review. Presented as a poster presentation at International Society for Traumatic Stress Studies (ISTSS) Conference, Dallas, TX.

Szabo, Y.Z., Warnecke, A.J., Newton, T.L., \& Valentine, J. (November 2016). Associations between rumination and posttraumatic symptoms: A systematic review and meta-analysis. Presented as a poster presentation at ISTSS, Dallas, TX.

Warnecke, A.J., Szabo, Y.Z., Burns, V., Fernandez-Botran, R., Miller, J., \& Newton, T.L. (November 2015). Sheltering for safety in community women with divorce histories. Presented as a poster presentation at ISTSS, New Orleans, LA.

Szabo, Y.Z., Miller, J.J., Fernandez-Botran, R., Burns, V.E., \& Newton, T.L. (March, 2015). Health Risks in Midlife Women: The Roles of Cumulative Trauma and Posttraumatic Stress. Presented as a poster presentation at the American Psychosomatic Society Conference, Savannah, GA.

Szabo, Y.Z., Fernandez-Botran, R., Miller, J.J, Lyle, K.B., Newton, T.L. (March 2014). Detection and Stress Reactivity of Interleukin-10 in Oral Fluids. Presented as a poster presentation at the American Psychosomatic Society Research Conference, San Francisco, CA.

*Invited Press Release through American Psychosomatic Society 
Fernandez-Botran, R., Miller, J.J., Burns, V.E., \& Newton, T.L. (November 2013). Chronically traumatized midlife women resistant to PTSD or recovered from PTSD have similar health-related quality of life. Presented as a poster presentation at ISTSS, Philadelphia, PA.

Szabo, Y.Z., Fleming, K.N., Fernandez-Botran, R., Miller, J.J. Burns, V.E., \& Newton, T.L. (November 2013). Past emotional/verbal abuse predicts current depression symptom clusters in post-abuse community-dwelling women. Presented as a poster presentation at ISTSS, Philadelphia, PA.

Szabo, Y.Z., Johnson, K., \& Brennan, P. (November, 2011). Perinatal complications as an early stressor: Associations with cortisol reactivity at six-months of age. Presented as a poster at American Biomedical Research Conference for Minority Students, St. Louis, MO.

\section{Regional or Local Conferences}

Szabo, Y., Chang, A., Antonel, B., Akhtar, M., Hosoda, M., \& Chancellor-Freeland, C. (April, 2012). The effect of gender and locus of control on speech performance and cortisol reactivity. Presented as a poster presentation at the Western Psychological Association Research Conference, San Francisco-Burlingame, CA.

\section{*Regional Research Award Recipient}

Burgess, O, Szabo, Y.Z, \& Hernandez, C. (May, 2011). The effects of sleep deprivation on cortisol and alpha-amylase reactivity. Presented as a Paper Presentation at the Spartan Psychological Association Research Conference (SPARC), San José, CA.

Kaiser, K., Szabo, Y.Z., Medina, M., \& Hosoda, M. (May, 2010). An examination of comprehension and evaluation of a speaker using native and foreign-accented speech. Presented as a Paper Presentation at SPARC, San José, CA.

\section{Ad Hoc Reviewing Experience}

October 2016

August 2014
Ad Hoc Reviewer for Patient Education and Counseling

Ad Hoc Reviewer for Journal of Interpersonal Violence 


\section{Research Experiences}

July 2016-

present

July 2012-

present

\section{Clinical Research in Posttraumatic Stress Disorder and Comorbid Anxiety Disorders}

Anxiety Disorders Lab, Michael E. DeBakey Veterans Affairs

Medical Center

Intensive Panic Control Treatment (iPCT)

Health Services Research \& Development (HSR\&D) PPO \#09-307

PI: Ellen Teng, PhD

Role: Psychology Intern

o Provide clinical interventions in context of research study examining intensive weekend format of Panic Control Treatment to examine effective treatments for anxiety disorders among veterans and aims to improve efficacy and increase accessibility

o Develop project that examines emotion dysregulation as a predictor of treatment outcomes in panic disorder

o Participate in structured writing team

\section{Stress \& Health Lab}

University of Louisville

Advisor: Tamara Newton, PhD (PI)

Life Experiences, Emotion and Stress Study

Psi Chi Graduate, GSC Research, and A\&S Research Grants

PIs: Tamara Newton, PhD, Yvette Szabo, MA

Role: Co-PI

o Designed, implemented and coordinated dissertation study on trauma exposure, emotion and cytokines in an undergraduate acute stress paradigm.

o Completed IRB protocol, train undergraduate and post baccalaureate research assistants and run participants

o Analyzed saliva samples for cytokine and protein content

Mind-Body Connections Study

Visionary Grant by the American Psychological Foundation PI: Tamara Newton, PhD

Role: Graduate Fellow, Research Associate, Co-study coordinator

o Assisted in design, implementation, and coordination of undergraduate acute stress study and 2 year follow-up

o Mentored of undergraduate and graduate students.

o Analyzed cytokines and protein in oral fluids using high sensitivity assays; Collected blood pressure and heart rate for research purposes 
Women's Stress and Aging Study (WOMSA)

NIH R21AG024902

PI: Tamara Newton, PhD

Role: Research Associate, study coordinator

o Coordinated longitudinal study of post-abuse women

o Disseminated projects examining psychological abuse, quality of life, and sheltering for safety; Data analysis using SAS statistical software

June 2010-

May 2012

Laboratory Experiences

Stress and Health Lab

July 2016

University of Louisville

o Psychophysiology

o Trained to find brachial artery and place cuff appropriately

o Collected blood pressure, heart rate and mean arterial pressure for research purposes

o Immunonology/Pathology

o Collect, store and prepare human saliva and oral mucosa trunsudate (OMT); experience with pipetting and preparing reagents.

o Analyzed samples using high sensitivity kits for cytokines; analyzed saliva for protein content using enzyme-linked immunosorbent assays (ELISA) kits, adjusted for flow rate and protein

June 2010-

International Neuroeconomics Institute Lab

May 2012

San José State University

o Endocrinology

o Collected, stored and prepared saliva samples; Experience with pipetting

o Analyzed salivary cortisol and alpha amylase using ELISA; select best fitting standard curve 


\section{Additional Specialty Research Experiences}

September 2013-

January 2014

June 2011-

August 2011

University of Louisville Grant Writing Academy (GWA)

School of Interdisciplinary and Graduate Studies,

o Applied for and was accepted into the GWA, a series of monthly workshops on finding funding sources, creating budgets, developing proposals, and managing awards

o Developed a unique research idea and proposal during the series and submitted for grant review

Summer Undergraduate Research at Emory (SURE) Scholar

Biosocial Underpinnings Involved in Learning and Development

$\mathrm{Lab}$

Emory University

Advisors: Patricia Brennan, $\mathrm{PhD}$ (PI), Katrina Johnson, $\mathrm{PhD}$

Preschool Medication Use and Childhood Outcome

Emory University Silvio O. Conte Center for the Neurobiology of Mental Disease (MH58922)

Specialized Center of Research on Sex and Gender Effects

Grant (MH68036). PI: Patricia Brennan, PhD

Role: SURE Scholar

o Applied for and was accepted into the SURE program, a full-time research experience that allows undergraduate students to learn specialty research skills

o Administered attention, executive function and frustration tasks and collected saliva samples from child participants of mothers who took medication during pregnancy;

o Examined relationship between perinatal complications and cortisol

\section{Predoctoral Internship Clinical Experiences}

July 2016 present

April 2017present

April 2017present
Michael E. DeBakey VA Medical Center, Houston TX

APA-Accredited Predoctoral Internship

Director of Training: Ellen Teng, $\mathrm{PhD}$

General Mental Health Clinic

Supervisor: Chloe Hoang, Ph.D.

○ Delivered Acceptance and Commitment Therapy (ACT) individually for veterans presenting with mood disorders

- Co-facilitated group therapy utilizing ACT for anxiety

\section{Neuropsychology - Mental Health Care Line}

Supervisor: Jane Booth, Ph.D.

o Provided neuropsychological assessments for Veterans to answer referral questions for Mental Health Care Line

- Wrote integrated reports and provided feedback to patients and their families. 
December 2016March 2017

December 2016March 2017

\section{August 2016- December 2016}

\section{August 2016- December 2016}

\section{Women's Health Center}

Supervisor: Alison Sweeney, PsyD

o Provided brief, gender-sensitive individual therapy for female veterans presenting to a primary care clinic. Presenting issues included anxiety, depression, medication adherence and grief.

o Completed focused intake interviews, placed consults as needed

o Attended Primary Care-Mental Health Team Meetings

\section{PTSD Clinical Team (PCT)}

Supervisor: M. Ashton Phillips-Benesh, $\mathrm{PhD}$

o Provided Cognitive Processing Therapy (CPT) individually to veterans of all eras presenting with PTSD and comorbid conditions.

o Co-facilitated Skills Training for Affective and Interpersonal Regulation (STAIR) group, provided STAIR individually

o Attended PCT meetings to learn about administration, case review and program evaluation relevant to this specialty clinic.

\section{Returning OEF/OIF Veterans Environment for Recovery}

Supervisor: Jill Wanner, PhD

○ Co-led group CPT as part of inpatient PTSD treatment unit with male combat veterans, many of which presented with comorbid substance use and personality disorders

- Completed admission interviews using the Clinical Assessment PTSD scale for DSM-5 (CAPS5)

- Served as psychology consult during interdisciplinary team meetings with psychiatry, social work, recreational therapy, occupational therapy, chaplain and nursing

\section{Acute Recovery Treatment Environment (ARTE)} Supervisor: Justin Springer, PhD

o Provided brief intervention to patients presenting with acute detoxification, severe mental illness, and suicidal ideation within a 32-bed inpatient unit

o Trained to competency in Motivational Interviewing; Led and co-led groups on ACT, Dialectical Behavioral Therapy, Cognitive Behavioral Therapy for inpatients

- Program Evaluation: Evaluate improvement in customer satisfaction following modification of unit; Presented results as part of Value Stream 


\section{Clinical Practica}

August 2015-

July 2016

June 2015-

June 2016

May 2015-

June 2016
Integrative Therapies Practicum

Noble H. Kelley Psychological Services Center, University of Louisville

Supervisor: Rich Lewine, $\mathrm{PhD}$

o Integrated empirically supported models of psychotherapy to tailor treatment for clients presenting with complex presentations, including comorbid diagnoses and personality disorders.

o Supervision: Supervised students providing services consistent with cognitive-behavioral theory, and theoretical integration of psychotherapy, including video review of sessions. Attended bimonthly group supervision to discuss models of supervision.

Clinical Graduate Teaching Assistant (CGTA) Noble H. Kelley Psychological Services Center (PSC) Supervisor: Bernadette Walter, PhD

o Completed phone intakes for therapy and assessment clients, coordinated crisis interventions with emergency response services as needed, crisis management for clients walking into and calling the PSC, clinical administration

o Conducted intake interviews to determine appropriateness of clients for services at the PSC; Wrote intake reports and provided case management and alternative resources for clients referred externally.

o Served as Community Outreach coordinator; organized tabling events at local health fairs, planned psychoeducational presentations, and coordinated participation in national screenings

o Supervision: Provided peer supervision to doctoral students at varying levels of development; Co-taught assessment and intake courses

\section{External Clinical Practicum}

Athena's Sisters, Louisville, KY

Supervisors: Bernadette Walter, PhD; Lindsey Gargatto, MSW,

o Developed competence working with women veterans, gained understanding of unique needs of women who exit the military, including issues of identity and military sexual trauma (MST); created referral list of providers that provide services geared towards military women

o Conducted brief clinical assessments and provided supportive counseling as needed with the goal of facilitating community referrals 
August 2014-

July 2015

\section{August 2013-}

August 2015

June 2013 June 2016
External Clinical Practicum

Department of Behavioral Health, Ft. Knox, KY

Supervisor: Charles Thomas, PsyD

o Developed competence with military culture working with active duty service members from the Army, Army National Guard, and Marines

o Collaborated with other mental health professionals as part of embedded behavioral health team

o Used empirically-supported treatments based on conceptualization of client's clinical presentations; used mindfulness-based, narrative, cognitive and behavioral techniques for anxiety and mood disorders, hoarding behaviors and PTSD

- Collaborated on diagnostic interviews for fitness for duty, chapter separation, recruiter and other psychological evaluations

\section{Cognitive Behavioral Therapy Practicum}

Noble H. Kelley Psychological Services Center

Supervisor: Janet Woodruff-Borden, PhD

o Used Cognitive-Behavioral Theory to develop collaborative case conceptualizations and develop treatment plans grounded in current empirical literature for individual therapy clients presenting with anxiety, mood, personality and trauma and stressor-related disorders

o Used Anxiety Disorder Interview Schedule (ADIS) to diagnose Axis I disorders

\section{Psychological Assessments Practicum}

Noble H. Kelley Psychological Services Center

Supervisor: David Winsch, PhD \& Bernadette Walter, $\mathrm{PhD}$

o Administered full diagnostic batteries for specific referral questions, including giftedness, learning disabilities, ADHD, and full diagnostic evaluations; Conducted collateral interviews

o Administered, scored and interpreted intelligence, achievement, personality, neuropsychological and psychodiagnostic tests, including the WAIS-IV, WISC-5, MMPI-II, MCMI, WJ-III

o Wrote integrated reports and provided feedback to clients 
August 2012-

August 2013
Geropsychological Assessment and Intervention Practicum

University of Louisville Geriatric Outpatient Hospital

Supervisor: Benjamin Mast, $\mathrm{PhD}$

o Administered neuropsychological batteries to assess for problems in later life such as Alzheimer's, dementia, and depression

o Reviewed medical records and imaging reports for fullperson evaluation; Conducted collateral interviews with other medical professionals and family members

o Wrote integrated report for physician and provided feedback to patients

o Served as neuropsychology consultant as part of an interdisciplinary team with physicians and social worker

\section{Specialized Trainings}

October 2016

Clinician Administered PTSD Scale for DSM 5 (CAPS5)

Michael E. DeBakey Veterans Affairs Medical Center

o Trainer: Anka Vujanovic, $\mathrm{PhD}$

o Learned to administer the CAPS5 and demonstrate reliability in coding

September 2016present

May 2016

January 2016

\section{Cognitive Processing Therapy VA Rollout and Certification}

CPT Implementation Program, National Center for PTSD

o Consultant: Catherine Hansen, $\mathrm{PhD}$

o Attended three day training on individual and group Cognitive Processing Therapy (CPT) with Kelly Pears, PhD and Lauren Graves, $\mathrm{PhD}$

o Pending completion of 6-month formal consultation period and licensure as a psychologist, will be a VA certified provider of CPT.

Life After Trauma: Using ACT to Revitalize Interrupted Lives Webinar, International Society for Traumatic Stress Studies

- Presenter: Robyn Walser, $\mathrm{PhD}$

- Overview of how to integrate values into trauma treatment

Trauma Focused Cognitive-Behavioral Therapy (TFCBT)

Web-based training, Medical University of South Carolina

o Completed web-based version of TFCBT, an approach to therapy that integrates trauma-sensitive approaches with cognitive behavioral theory 
October 2015

September 2015

May 2015

\section{Safe Zone Training}

University of Louisville LGBT Center

o Attended a two-day training on how to provide an atmosphere of support and understanding for LGBT individuals; learn about advocating against homophobic and heterosexist comments

\section{Suicide Prevention Training}

Web-based training, Suicide Prevention Resource Center

o Completed web-based training on assessing and managing risk in clients with suicidal ideation

\section{Operation Immersion}

Wendall H. Ford Regional Training Center, Kentucky National Guard

o Attended a four-day intensive training on military culture for civilians in mental health fields; Participated in physical training, field training, combat simulations, and urban warfare exercises

o Attended seminars taught with focus on trauma-informed care, combat- related stress and suicide prevention (using ACE protocol); Key themes included basic training, mobilization, deployment and demobilization

\section{Teaching Experiences}

Clinical Graduate Teaching Assistant (CGTA)

Summer 2015

Spring 2016

\section{Psyc 693: Interviewing Skills Practicum}

o Instructed first year graduate students in basics of interviewing, provided feedback to student reflections, facilitated role plays

o Independent seminars facilitated: initial foundations, suicide and dangerousness assessment

\section{Psyc 681: Assessment II}

o Provided instruction and feedback to first year graduate students in administering and scoring cognitive assessments

o Audio-digital review of practice administration, with scoring and feedback for students 
Graduate Teaching Assistant (GTA)

2014-2015

Guest Lectures

2014-2015

2014-2015

2014-2015

Summer 2013
Psyc 301: Quantitative Methods in Psychology

o Taught two lab sections of 25-30 students

o Graded all course work, proctored exams and managed grades through BlackBoard, met with students individually during office hours

\section{Psyc 385: Abnormal Psychology}

Lecture: Trauma \& Stressor Related Disorders, Spring 2014

\section{Psyc 301: Quantitative Methods}

Lecture: Independent Samples t-tests, Fall 2014

Lecture: Errors, Effect Size and Power, Spring 2015

\section{University of Louisville Graduate Teaching Academy}

o Attended monthly workshops on using rubrics, managing classroom dynamics and using technology with the goal of thinking critically about teaching; Reflecting on teaching goals, drafted teaching philosophy

o $\quad$ Presented microteaching sessions with other interdisciplinary GTAs on PollEverywhere, a polling technology. Presented session individually and both gave and received peer feedback.

\section{Graduate Course: Practicum in College Teaching}

o Learned to use Blackboard to manage grades, use discussion boards, and create assignments; Focused on designing clear syllabi and effective lectures to disseminate important information and generate discussion

o Discussed increasing motivation by utilizing several modes of teaching, diverse media and being sensitive to different learning styles

\section{Community Workshops and Presentations}

Warner, A., Szabo, Y.Z., \& Springer, J.R. (November 2016). Burnout. Presentation for incoming nursing students at Michael E. Debakey Veterans Affairs Medical Center, Houston, TX.

Szabo, Y.Z. \& Bayley-Veloso, R.C. (May 2016). Trauma Processing and Courageous Next Steps. Half day workshop, Sisters Healing Sisters Retreat. Life Adventure Center, Versailles, KY. 
Szabo, Y.Z., Bayley-Veloso, R.C., Altman, J., McDonough, S.R. (April 2016). Extending Self-Compassion amongst Shifting Identities. Presentation and workshop for Athena's Sisters, Louisville, KY.

Szabo, Y.Z., Bayley-Veloso, R.C., Rebholz, W.N., Knight, H.M., \& Richards, A.E. (May 2015). Self- esteem and empowerment. Presentation and workshop for Athena's Sisters, Louisville, KY.

Szabo, Y.Z. (April 2014). Career Opportunities in Psychology. Presented to Introductory Psychology Class, Corydon Central High School, Corydon, IN.

Rebholz, W. \& Szabo, Y.Z. (June 2013). Stress Management and your Career. Presented to Dress for Success JOBS program, Louisville, KY.

\section{Community Service}

October 2016

\section{Inpatient Mental Health Treatment Planning Recovery Committee}

Michael E. DeBakey Veterans Affairs Medical Center

o Worked with supervisor and other trainees to improve veteran experience

o Assisted in revising acute recovery treatment plan templates to reflect recovery oriented language

August 2015 June 2016

August 2014-

August 2015
Graduate Student Ambassador, University of Louisville School of Interdisciplinary and Graduate Studies,

o Served as an ambassador to increase student recruitment and retention

o Answered questions as part of a panel, provided campus tours and assisted at events for current and prospective graduate students, including doctoral hooding ceremony and orientation

Advocacy Coordinating Team Campus Representative American Psychological Association for Graduate Students

o Disseminated APA announcements to involve peers in advocacy efforts; Learned more about advocacy through specialized trainings

o Created and maintained a Facebook page on Intimate Partner Abuse Awareness with the aim of spreading knowledge and resources to reduce stigma, end and prevent intimate partner abuse 
January 2014

January 2015

Fall 2013

Fall 2014

July 2013July 2016

June 2013-

February 2015

June 2011-

April 2012
University of Louisville- Clinical Psychology PhD Interviews

Department of Psychological \& Brain Sciences

o Assisted in coordinating applicants for the 2014 and 2015 classes

o Served as a liaison between current students and applicants to coordinate transportation

Disability Resource Center Note-taker

Disability Resource Center (DRC), University of Louisville

o Completed note-taking training through the DRC

o Served as a note-taker in graduate courses for a student with a disability.

\section{Graduate Student Peer Mentor}

Clinical Psychology Doctoral Program, University of Louisville

o Support first year clinical psychology graduate student; Train mentee in lab procedures

o Initiate regular check-ins and share experiences to facilitate transition into graduate school

\section{Hospital Advocate/Community Outreach}

Center for Women and Families, Louisville, KY

o Accompanied domestic violence and sexual assault victims to hospital for examination; Presented clients with psychoeducational materials about intimate partner violence, sexual assault and the effects of trauma. Provided crisis intervention; safety planned with clients

o Attended community events to disseminate knowledge about domestic violence and sexual assault; answered questions; engaged individuals of all ages and backgrounds

o Competed 40-hour training on domestic violence, sexual assault, effects of trauma and trauma informed care.

\section{Rape Crisis Counselor/Hospital Advocate} YWCA Rape Crisis Center, San Jose, CA

o Answered 24-hour hotline calls; provided crisis intervention and shared community resources

o Accompanied victims of sexual assault to hospital for examination and treatment; advocated for client to sexual assault response team nurse and police officers

o Completed 40-hour training on sexual assault, human trafficking, and domestic violence; attended four inservice (continuing education) seminars/training 


\section{Professional Associations}

2015-present

2014-present

2013-present

2010-2012

2009-2016
American Psychosomatic Society

Graduate Student Member

American Psychological Association

Division 56, Trauma Psychology Graduate Student Member (APAGS)

Advocacy Coordinating Team Campus Representative, 2014-

2015

International Society for Traumatic Stress Studies (ISTSS)

Graduate Student Member

Minority Access to Research Careers (MARC) program

San José State University program

Psi Chi, the International Honors Society in Psychology

President, Vice-President and Student-Faculty Liaison, SJSU

Chapter

Graduate Student Member, University of Louisville Chapter 